\title{
WILEY-VCH
}

DOI: 10.1002/aenm.201801892

Article type: Full Paper

\section{Self-Assembled Hole Transporting Monolayer for Highly Efficient Perovskite Solar Cells}

Artiom Magomedov, Amran Al-Ashouri, Ernestas Kasparavičius, Simona Strazdaite, Gediminas Niaura, Marko Jošt, Tadas Malinauskas, Steve Albrecht* and Vytautas Getautis*

\author{
A. Magomedov, E. Kasparavičius, Dr. T. Malinauskas, Prof. Dr. V. Getautis \\ Department of Organic Chemistry, Kaunas University of Technology, Radvilenu pl. 19, \\ Kaunas, LT-50254, Lithuania \\ E-mail: vytautas.getautis@ktu.lt
}

A. Magomedov, A. Al-Ashouri, Dr. M. Jošt, Dr. S. Albrecht

Institute for Silicon Photovoltaics, Helmholtz-Zentrum Berlin, Young Investigator Group for Perovskite Tandem Solar Cells, Kekuléstr. 5, Berlin, D-12489, Germany

E-mail: steve.albrecht@helmholtz-berlin.de

Dr. S. Strazdaite, Prof. Dr. G. Niaura

Department of Organic Chemistry, Center for Physical Sciences and Technology, Sauletekio Ave. 3, LT-10257, Vilnius, Lithuania

Keywords: self-assembled monolayers, hole transporting materials, perovskite solar cells

The unprecedented emergence of perovskite-based solar cells (PSCs) is accompanied by an

intensive search of suitable materials for charge-selective contacts. For the first time we use a hole-transporting self-assembled monolayer (SAM) as the dopant-free hole-selective contact in p-i-n PSCs and demonstrate a power conversion efficiency of up to $17.8 \%$ with average fill factor close to $80 \%$ and undetectable parasitic absorption. SAM formation is achieved by simply immersing the substrate into a solution of a novel molecule V1036 that binds to the ITO surface due to its phosphonic anchoring group. We further characterize the SAM and its modifications by Fourier-transform infrared and vibrational sum-frequency generation spectroscopy. In addition, photoelectron spectroscopy in air was used for measuring the ionization potential of the studied SAMs. This novel approach is also suitable for achieving a conformal coverage of large-area and/or textured substrates with minimal material consumption and can potentially be extended to serve as a model system for substrate-based perovskite nucleation and passivation control. Further gain in efficiency can be expected upon SAM optimization by means of molecular and compositional engineering. 


\section{WILEY-VCH}

\section{Introduction}

In a strikingly short period of time, solar cells with organic-inorganic perovskite absorbing layers have surpassed $20 \%$ power conversion efficiency (PCE), with a current record efficiency of $23.3 \% .{ }^{[1]}$ So far, the published record results for perovskite solar cells (PSCs) ${ }^{[2]}$ were achieved in n-i-p configuration (in literature often referred to as "regular" PSCs) with a combination of a compact and mesoporous $\mathrm{TiO}_{2}$ layer as an electron transporting material (ETL) deposited on a transparent conductive oxide substrate. So called "planar" regular solar cells have also been reported using compact $\mathrm{TiO}_{2}, \mathrm{SnO}_{2}$, fullerene-based derivatives or a combination of these layers. ${ }^{[3-6]}$ Recently, the p-i-n configuration (in literature often referred to as "inverted" PSCs), where first the hole transporting materials (HTMs) are deposited on the TCO, gained significant attention with reported efficiency over $20 \% .^{[7,8]}$ P-i-n PSCs have several advantages in comparison to the n-i-p architecture. First, high temperature annealing, which is required for the $\mathrm{TiO}_{2}$ layer formation, is avoided. Second, they are known to have much less pronounced hysteresis, leading to virtually „hysteresisfree“ devices, ${ }^{[9]}$ even though it can still be detected under certain conditions. ${ }^{[10,11]}$ Third, much cheaper copper can be used instead of gold as a metal contact layer. ${ }^{[7]}$ Next, no doping is needed for the charge selective contacts which might improve the long-term stability as dopants of spiro-OMeTAD are known to reduce device stability. ${ }^{[12]}$ Finally, the p-i-n configuration was shown to enable higher tandem efficiency potential due to less parasitic absorption in the front contact ${ }^{[13,14]}$ and thus $\mathrm{p}-\mathrm{i}-\mathrm{n}$ PSCs have a great potential for further development.

Currently, most popular hole transporting materials for p-i-n PSC are p-type polymers (e.g. PTAA,${ }^{[8,15]}$ Poly-TPD,${ }^{[16,17]}$ PEDOT:PSS ${ }^{[18,19]}$ ), or inorganic metal oxide (e.g. $\mathrm{NiO}_{\mathrm{x}}{ }^{[20]}$ ), which are deposited by a spin-coating technique. However, spin-coating is not suitable for largescale production due to low throughput and large waste of materials. As an alternative, vacuum deposition technique can be utilized for the HTM formation (e.g. for TaTm ${ }^{[21]}$ ), yet 


\section{WILEY-VCH}

its application is limited to small molecules, which are compatible with sublimation but usually not with solution-processed perovskites due to their low resistance to the used solvents.

In a recent work by M. Stolterfoht et.al. ${ }^{[8]}$ it was shown, that reduction of the HTM film thickness leads to increase in the fill factor $(F F)$. However, as the films are getting thinner, open-circuit voltage $\left(V_{o c}\right)$ sharply drops, possibly due to the incomplete coverage of indium tin oxide (ITO), leading to a direct contact between perovskite and ITO and thereby enhancing the interface recombination.

The formation of a self-assembled monolayer (SAM) on TCO circumvents the disadvantages of spin-coating or vacuum deposition, while offering the benefits of uniformly formed layers with minimized thickness. ${ }^{[22,23]}$ SAM HTMs would have minimal parasitic absorption, very low material consumption, would help to avoid doping procedure, and could be adopted for the large area production of solar cells. Moreover, due to the covalent linking to the substrate surface these layers are relatively tolerant against perovskite processing and could potentially ensure a conformal coverage of textured surfaces. Therefore, SAM HTMs would be perfect candidates for direct integration of monolithic perovskite/silicon solar on textured silicon or rough CIGS substrates.

Molecules with phosphonic acid head groups are known to form densely packed, uniform monolayers on various oxides, ${ }^{[22,23]}$ in particular on ITO by forming strong bidentate/tridentate bonds with the oxide surface, ${ }^{[24,25]}$ which was shown to occur even at room temperatures. ${ }^{[26]}$ They have been utilized for various applications, e.g. in dye-sensitized solar cells (DSSCs) ${ }^{[27]}$ and in electrochromic devices. ${ }^{[28,29]}$ However, up to date there are only several reports on the synthesis and application of hole transporting molecules, functionalized with phosphonic acid groups. Applications can be found in organic light-emitting diodes (OLEDs) ${ }^{[30]}$ where HTM SAMs were used for better charge injection, or in SAM field-effect transistors (SAMFETs). ${ }^{[31,32]}$ 


\section{WILEY-VCH}

Recently, several reports were published by Y. Hou et.al. on the use of a phosphonic acidbased mixed $\mathrm{C}_{60} /$ organic SAM as an ETL in n-i-p PSCs, replacing $\mathrm{TiO}_{2} \cdot{ }^{[33,34]}$ Siloxanefunctionalized $\mathrm{C}_{60}$ SAMs were used by P. Topolovsek et.al. in a similar fashion. ${ }^{[35]}$ In the work of X. Lin et.al. ${ }^{[36]}$ insulating SAMs on gold were used to achieve surface dipole assisted charge extraction. However, to the best of our knowledge, no hole-transporting SAMs for PSCs have been reported up to date.

In this work, a new hole transporting material V1036, with a phosphonic acid anchoring group was synthesized and used for the formation of a self-assembled hole-transporting monolayer (SA-HTM) on ITO. For the first time, p-i-n PSCs with a SA-HTM were constructed and showed a very promising power conversion efficiency close to $18 \%$ using a mixed cation/mixed halide perovskite composition, the so called "triple cation" perovskite. ${ }^{[37]}$ We believe that this strategy can be further developed by introducing other well-known HTM fragments, which eventually could lead to even higher efficiencies. Furthermore, use of the SAMs opens possibilities for the substrate-based perovskite nucleation and passivation control.

\section{Results and Discussion}

For this purpose, dimethoxy-diphenylamine substituted carbazole V1036, functionalized with phosphonic acid, was synthesized. Dimethoxydiphenylamine substituted carbazole fragment can be found in several efficient $\mathrm{HTMs}^{[38-40]}$ for regular perovskite solar cells, and reactive Nitrogen in the 9-th position of carbazole can be further used for the functionalization with a phosphonic acid anchoring group.

Synthesis was done in a 4-step synthetic procedure, starting from commercially available materials (Scheme 1A). 3,6-Dibromocarbazole was alkylated with 1,2-dibromoethane to give intermediate compound 1. In the next step, by the means of Arbuzov reaction, aliphatic bromide was transformed into phosphonic acid ethyl ester 2. Dimethoxydiphenylamine 


\section{WILEY-VCH}

fragments were introduced to yield compound $\mathbf{3}$ via palladium-catalyzed Buchwald-Hartwig amination reaction. Finally, cleavage of the ester with bromotrimethylsilane resulted in phosphonic acid V1036. Structures of the synthesized compounds were confirmed by means of ${ }^{1} \mathrm{H}$ and ${ }^{13} \mathrm{C}$ NMR spectroscopy. A more detailed description of the synthetic procedures is available in the SI. A relatively high overall yield of $46 \%$ for the 4-step synthesis is achieved due to the simplicity of most of the stages, making V1036 a promising material for the practical application.

In an inverted PSC light first passes through the HTM layer when illuminated from the glasssubstrate side, thus it is important to minimize parasitic absorption of this layer. Optical properties of V1036 were investigated by means of UV/vis spectroscopy (Figure 1A). A strong $\pi-\pi^{*}$ absorption band, with $\lambda_{\max }=304 \mathrm{~nm}$, as well as a weaker $\mathrm{n}-\pi^{*}$ band in the 350 $450 \mathrm{~nm}$ region, which is characteristic for the dimethoxydiphenylamine 3,6-substituted carbazole chromophoric system, ${ }^{[38]}$ can be observed. In comparison to PTAA $\left(\lambda_{\max }=387 \mathrm{~nm}\right)$, V1036 has an absorption maximum in a shorter wavelength range and weaker absorption in the visible range.

Additionally, UV/vis absorption of a PTAA layer and V1036 SAM on ITO was measured as displayed in Figure 1B. The SAM is formed on the ITO substrate by immersing the substrate into a $1 \mathrm{mM}$ solution of $\mathbf{V 1 0 3 6}$ in isopropanol (see ESI for more details) for 20 hours.

Subsequently, the substrate is blown dry with nitrogen and then annealed for $1 \mathrm{~h}$ at $100^{\circ} \mathrm{C}$ on a hotplate, before being washed with isopropanol and chlorobenzene. As can be seen from Figure 1B, the V1036 SAM has a negligible influence on the absorption of ITO $(<1 \%)$, therefore no parasitic absorption is expected. Under the given measurement uncertainty of $\sim 1 \%$ of the spectroscopy setup, the UV/vis spectra together with optical simulations allow us to estimate an upper bound for the thickness of the V1036 layer on ITO (see ESI for more details). Assuming a previously reported surface packing density of $0.7 \mathrm{~nm}^{2}$ per molecule for a similarly sized molecule, ${ }^{[30]}$ the simulation reveals that the layer thickness must be below 


\section{WILEY-VCH}

$2 \mathrm{~nm}$ in order to show an absorption of under $1 \%$ at $375 \mathrm{~nm}$. The vertical size of the molecule (DFT calculations, Figure S20, S21) is $\sim 1.5 \mathrm{~nm}$, pointing towards monolayer thickness. Thermal decomposition of the V1036 was investigated by means of thermogravimetric analysis (TGA). In Figure S1, a TGA heating curve of V1036 is shown, from which the 95\% weight loss temperature $\left(T_{d e c}\right)$ of $343^{\circ} \mathrm{C}$ was determined. $T_{d e c}$ is high enough to make this material suitable for the practical applications in optoelectronic devices.

The first indication of a surface modification is the change of the contact angle of perovskite solution on the treated ITO substrates. In previous reports, SAM solutions mixed with smaller aliphatic molecules as fillers were used to improve the quality of the formed monolayers. ${ }^{[41,42]}$ Following this insight, we mixed our SAM solution with butylphosphonic acid (C4) (Scheme 1B) in different ratios, as aliphatic phosphonic acids are known to form dense insulating monolayers on oxides, ${ }^{[43,44]}$ and investigated the influence on contact angle and solar cell device performance. The total concentration of both phosphonic acids in the solutions was kept at $1 \mathrm{mM}$, such that e.g. a $50 \%$ V1036 50\% C4 SAM solution consists of $0.5 \mathrm{mM} \mathrm{V1036}$ and $0.5 \mathrm{mM}$ C4. Figure 2 shows contact angle measurements using "triple cation" perovskite solution in DMF:DMSO (4:1; v:v) as a probing liquid for different compositions of the immersion solution. As can be seen in Figure 2 and Table S1, for PTAA, 100\% V1036 SAM, and $100 \% \mathrm{C4}$ SAM contact angles are $42.6^{\circ}, 26.3^{\circ}$, and $60.5^{\circ}$ respectively. For the mixed SAMs, the contact angle gradually changes with changing molar ratio between $\mathbf{C} 4$ and V1036, confirming the presence of both species on the ITO surface. The smooth transition of the contact angle values confirms that the ratio of $\mathbf{C 4}$ to V1036 on the surface can be modified in a controllable fashion via composition of the immersion solution. Differences in contact angle correlate with the polarity of the material, giving the largest value for non-polar aliphatic $100 \%$ C4 SAM, and lowest value for 100\% V1036 SAM because of its polar methoxy functional groups. 


\section{WILEY-VCH}

To confirm that the surface modification is indeed induced by V1036 molecules, FTIR spectra of the studied SAMs on ITO substrates were recorded (Figure 3A) and compared to the spectrum of bulk V1036 compound dispersed in a potassium bromide (KBr) tablet (Figure 3B). The spectrum of a $100 \% \mathbf{V 1 0 3 6}$ SAM exhibits two intense bands at 1238 and $1503 \mathrm{~cm}^{-1}$ along with lower intensity components near 1442, 1461, and $1485 \mathrm{~cm}^{-1}$ (Figure 3A, (a)). All observed features in the monolayer spectrum are close to the absorption bands visible in the infrared spectrum of bulk V1036, confirming its presence on the surface of the ITO substrate. The most intense band at $1503 \mathrm{~cm}^{-1}$ is associated with $\mathrm{C}=\mathrm{C}$ in-plane stretching vibration of aromatic rings of the carbazole structure ${ }^{[45-47]}$ with some contribution from $\mathrm{C}=\mathrm{C}$ in-plane stretching vibration of $p$-methoxy-phenyl groups. ${ }^{[48]}$ Stretching vibrations of $\mathrm{C}-\mathrm{N}$ bonds ${ }^{[46,47]}$ are visible as an intense band near $1238 \mathrm{~cm}^{-1}$. Two medium intensity bands located in the vicinity of $1438-1442$ and $1461-1466 \mathrm{~cm}^{-1}$ contain a high contribution from symmetric and asymmetric $\mathrm{CH}_{3}$ deformation vibrations of the methoxy group. ${ }^{[48]}$ The integrated absorbance intensity of the band near $1503 \mathrm{~cm}^{-1}$ was found to decrease for the SAM prepared from solution containing mixture of $\mathbf{V 1 0 3 6}$ (10\%)and $\mathbf{C 4}(90 \%)$ down to 0.62 of the relative intensity compared to the $100 \%$ V1036 SAM (relative intensity 1.00), indicating a decrease in surface coverage by the V1036 compound in the mixed SAM. Clearly, the decrease in surface coverage for the V1036 compound is not as high as could be expected from the C4 to V1036 molar ratio (1:9) in the adsorption solution, which indicates a higher surface affinity for V1036 compared to $\mathbf{C 4}$. $100 \%$ V1036 monolayer showed no difference after the sample was kept for 25 days at ambient temperature in air (Figure S3), suggesting good stability of the formed monolayer.

An additional argument for the absence of multilayers can be deducted from an analysis of FTIR spectra of samples prepared in adsorption solutions containing different concentrations of the V1036 compound (Figure S2). Vibrational bands of surface layers prepared from 0.1 and $1 \mathrm{mM}$ adsorption solutions are very similar both in peak positions and intensities. We 


\section{WILEY-VCH}

found that the full width at half maximum (FWHM) of $1503-\mathrm{cm}^{-1}$ band increases just slightly for the layer prepared from $1 \mathrm{mM}$ solution. The ratio of integrated absorbance intensity, was found to be $\mathrm{A}(0.1 \mathrm{mM}) / \mathrm{A}(1 \mathrm{mM})=0.86$ for the band near $1503 \mathrm{~cm}^{-1}$. Small differences in FTIR spectra of V1036 on ITO prepared from 0.1 and $1 \mathrm{mM}$ adsorption solutions suggest absence of multilayer material for our studied samples.

To further investigate SAMs on the ITO surface and assess differences in layer ordering, we performed vibrational sum-frequency generation spectroscopy (VSFG) on the same substrates as used for the FTIR spectra. Figure S4 in the supporting information shows the VSFG spectra of our SAMs in the spectral region $1150-1300 \mathrm{~cm}^{-1}(\mathrm{~A})$ and $1400-1600 \mathrm{~cm}^{-1}$ (B). Two peaks at $\sim 1237 \mathrm{~cm}^{-1}$ (Figure S4A, (a)) and $\sim 1490 \mathrm{~cm}^{-1}$ (Figure S4B, (a)) were identified in the spectra of the $100 \%$ V1036 SAM substrate. Those two bands correspond to the two most intense vibrational bands seen in the FTIR spectra of the same monolayer (see Figure 3A, (a)). The shape of the resonance centered at $\sim 1490 \mathrm{~cm}^{-1}$ resembles an asymmetric Fanolike resonance curve and also appears to be shifted compared to its frequency in the FTIR spectra $\left(\sim 1503 \mathrm{~cm}^{-1}\right)$. This can be explained by an interference between the resonant signal and a substantial non-resonant SFG signal from the ITO substrate, leading to spectral distortions as can be deduced from Eq. S1. ${ }^{[49]}$

No vibrational bands were identified in the VSFG spectrum of a $10 \% \mathbf{V 1 0 3 6} 90 \% \mathbf{C 4}$ mixed SAM. The FTIR spectra showed that the surface coverage of V1036 in the mixed SAM corresponds to $\sim 62 \%$ of the surface coverage of a pure V1036 SAM. Thus, the VSFG signal of a monolayer with such surface coverage should be still detectable; however, no signal was registered. We conclude that a monolayer prepared from a mixed solution results in a more disordered structure compared to a monolayer from a pure V1036 solution, since the measured VSFG signal is proportional to the molecular ordering of the probed molecules. ${ }^{[50]}$ Good matching of the energy levels between the absorber and charge selective contacts is an important requirement for efficient device operation. The work function of bare ITO was 


\section{WILEY-VCH}

previously measured to be $4.6 \mathrm{eV}^{[3]}$ by means of ultraviolet photoelectron spectroscopy (UPS). The perovskite valence band edge and conduction band edge energies are measured to be in the range of 5.6-5.8 eV and 3.8-4.2 eV respectively. ${ }^{[51-53]}$ A good hole selective contact should have an ionization potential $\left(I_{p}\right)$ close to the perovskite valence band edge energy and a large energetic offset between the electron affinity $(E A)$ and the perovskite conduction band edge. In order to measure the $I_{p}$ of the studied SAMs, we performed photoelectron spectroscopy in air (PESA) measurements on ITO/SAM samples and bulk V1036 (Table 1, Table S2, Figure S5-S8). For a PTAA film, spin-coated from a $2 \mathrm{mg} / \mathrm{ml}$ toluene solution on ITO, an $I_{p}$ value of $5.18 \mathrm{eV}$ was obtained, which is, within the measurement uncertainty of $\sim 0.03 \mathrm{eV}$, the same as a previously reported value of $5.16 \mathrm{eV} \cdot{ }^{[54]}$ Bulk $\mathbf{V 1 0 3 6}$ showed an $I_{p}$ of $5.04 \mathrm{eV}$, which is a typical value for this chromophore. ${ }^{[38]}$ For the $100 \%$ V1036 SAM formed on ITO, $I_{p}=4.98 \mathrm{eV}$ was obtained, which is in good agreement with the bulk material value. The mixed SAMs with a $10 \%$ to $50 \%$ of $\mathbf{V 1 0 3 6}$ showed $I_{p}$ in a range of $5.06-5.09 \mathrm{eV}$, with the highest value determined for the $10 \% \mathrm{V1036} 90 \% \mathbf{C 4}$ composition. $I_{p}$ values of these V1036:C4 mixtures are more suitable for efficient hole extraction ${ }^{[55]}$ than $100 \%$ V1036, or 5\% V1036 95\% C4 SAMs $\left(I_{p}=5.01 \mathrm{eV}\right)$. These results further suggest that the ionization potential might be potentially controllable by mixing different SAM molecules, opening up the possibility to easily adapt to different absorbers by choosing a suitable molar ratio between HTM SAM molecule and filler molecule. Electron affinity of the SAMs was calculated to be in a range of 2.23-2.34 eV (Table 1) which is close to that of PTAA $(2.22 \mathrm{eV})$.

Next, to ensure that perovskite crystal formation on the SAM yields a homogenous film with reasonable grain size, we compare scanning electron microscopy (SEM) micrographs of "triple cation" perovskite films on the SAMs and on a PTAA-coated substrate. As can be seen in Figure 4 and Figure S19, the grain size of the perovskite is dependent on the monolayer composition. For the SAMs obtained from solutions containing 50\% and 100\% V1036, 


\section{WILEY-VCH}

significantly smaller grains were obtained, which can be attributed to the better wetting of the perovskite solution. ${ }^{[56]}$ On the other hand, $10 \%$ and 25\% V1036 SAMs demonstrated very similar morphology to that of the control film on PTAA.

The novelty of our approach lies within the usage of a hole transporting fragment as a monolayer building block, which acts as a hole contact in PSCs. To demonstrate the efficient hole extraction and transport of holes to the TCO, we fabricated p-i-n PSC devices in a ITO/HTM/Perovskite/ $\mathrm{C}_{60} / \mathrm{BCP} / \mathrm{Cu}$ architecture, ${ }^{[8]}$ using "triple cation" perovskite ${ }^{[37]}$ as an absorbing layer. More details on device fabrication can be found in the ESI.

The impact of the ratio between the charge transporting V1036 and the electrically inactive filler molecule $\mathbf{C 4}$ on the device performance was studied first. As can be seen in Figure $\mathbf{5}$ and Table 2, the best PCE is achieved with the $10 \% \mathbf{V 1 0 3 6} 90 \% \mathbf{C 4}$ mixed SAM. $J_{s c}$ is almost the same for all SAM compositions, showing very small spread. $F F$ values of the best performing devices are also very close, yet the results are more spread, and on average the best result is obtained for 10\% V1036 90\% C4 and 25\% V1036 75\% C4 SAMs. Out of all performance parameters, the most pronounced influence of the $\mathbf{C 4 : V 1 0 3 6}$ ratio was observed in the open-circuit voltage $V_{o c}$. The better performance of the mixed SAMs compared to the pure SAMs can be rationalized based on the several aspects. Firstly, with the addition of $\mathbf{C 4}$, the wettability of the perovskite solution was decreased, which was previously shown to potentially result in better device performance due to an improved film morphology. ${ }^{[56]}$ This is in agreement with the SEM study of this work (Figure S19). Secondly, mixing with C4 resulted in slightly higher $I_{p}$, making it closer to the perovskite valence band, which is known to give higher $V_{o c}$ in case of the dopant-free HTMs. ${ }^{[55]}$ Indeed, in this work the highest $V_{o c}$ is obtained by the SAM mixture with the highest $I_{p}(10 \%$ V1036 $90 \%$ C4). Thirdly, it was shown by D. Moia et al., ${ }^{[57]}$ that hole transport between dye monolayer molecules in DSSCs accelerates recombination. By introducing insulating molecules in between, this process has diminished, thus giving higher $V_{o c}$ values. Finally, small insulating $\mathbf{C 4}$ molecules could 


\section{WILEY-VCH}

reduce direct contact of the perovskite with ITO by filling potential gaps left by the larger V1036 molecule, thus reducing interfacial recombination. This assumption is supported by the fact that HTM-free devices with bare ITO yield very low performance, mainly due to a strong reduction of $V_{o c}$ (Figure S9). Further reduction of the ratio from the $10 / 90$ to $5 \% \mathbf{V 1 0 3 6}$ and 95\% C4 SAM led to poor wetting by the perovskite solution and thus suboptimal film formation and device performance.

In principle, a variety of filler molecules can be used instead of $\mathbf{C 4}$. The length of the alkyl chain is known to have impact on the ordering of the SAM. ${ }^{[58]}$ Thus, to study the influence of the length of aliphatic phosphonic acid on the overall device performance, we tested ethylphosphonic (C2), and $n$-hexylphosphonic (C6) acids as well. It was impossible to form a perovskite film on $10 \%$ V1036 90\% C6 SAM due to very bad wetting. Devices with C2 filler gave slightly lower performance compared to using $\mathbf{C 4}$ as a filler molecule, due to a reduction in $V_{o c}$ and $J_{s c}$ (Figure S10). Such behavior can be attributed to a reduction of electronblocking properties upon reduction of the chain length of the filler molecule. ${ }^{[44]}$ To compare the SAM HTM performance to a well-established procedure in p-i-n PSC fabrication, solar cells with pristine PTAA ${ }^{[7,8]}$ as a HTM were constructed. As can be seen from Figure 6A, best-performing SAM devices (10\% V1036 90\% C4) showed a reverse scan PCE of $17.8 \%$, which is slightly lower than that of the device with PTAA (19.2\%) as the HTM. A stabilized efficiency from maximum power point tracking of 17.1\% (Figure 6A, inset) and only a small difference between forward and reverse scans (Figure S11) was measured at a high voltage sweep speed of $250 \mathrm{mV} / \mathrm{s}$. Additionally, we performed a stability comparison. Both devices showed a comparable shelf lifetime stability (Figure S16), with $\sim 95 \%$ and $\sim 94 \%$ of the maximal performance for most stable PTAA and SAM-based devices respectively retained after 180 days of storage $\left(\mathrm{N}_{2}\right.$, dark, room temperature). Considering that we here compare a monolayer to a dense polymeric film, the insignificant difference in stability is a remarkable fact. 


\section{WILEY-VCH}

To have a conclusive comparison between PTAA and SAM device performance parameters, a statistical study was conducted. The results are presented in Table 3 and Figures S12-S15. On average, $J_{s c}$ values are $\sim 0.3 \mathrm{~mA} \cdot \mathrm{cm}^{-2}$ higher for SAM devices. The reason behind the higher $J_{s c}$ of the SA-HTM-based PSCs compared to PTAA-based PSCs can be directly elucidated by external quantum efficiency (EQE) measurements performed on full devices. Figure 6B shows that the gain in current stems from a higher EQE in the range from 350 to $400 \mathrm{~nm}$. It can be attributed to the reduced absorption from the HTM, as previously demonstrated by UV/vis absorption measurements (Figure 1B). $J_{s c}$ values, obtained by integration of the EQE data, are in a close agreement with $J_{s c}$ values obtained from $\mathrm{J}-\mathrm{V}$ scans (within 1-2\%). FF values are on a high level for both device classes with a slight advantage for SAM devices, which is remarkable considering that only a single molecule layer yields sufficiently good selectivity, high charge extraction and shunt resistance needed for such high average $F F$ values (close to $80 \%$ ). Electrochemical impedance spectroscopy and dark JV measurements (Figures S22-S25) further confirm the high charge extraction efficiencies of SAM-based devices. The PCE is mainly limited by $V_{o c}$, which will be the subject of further optimization and can be addressed by structurally more preferred hole transporting fragments.

\section{Conclusion}

In conclusion, a new promising HTM formation concept was presented in this work. For this purpose, a new molecule V1036, containing a hole transporting fragment and phosphonic acid group, was synthesized and used for the formation of self-assembled HTMs on ITO surfaces. The presence of $\mathbf{V 1 0 3 6}$ on the surface of the ITO was confirmed by FTIR, VSFG, contact angle, and $I_{p}$ measurements. It was demonstrated that the addition of a small molecule, resulting in mixed SAMs, can have a positive impact on overall performance of SA-HTMbased devices, reaching a PCE of $17.8 \%$ for a $10 \%$ V1036 $90 \%$ C4 SAM-based device. The small amount of V1036 needed for the mixed SAM formation can be attributed to its substantially higher surface affinity compared to $\mathbf{C 4}$. Due to the negligible parasitic 


\section{WILEY-VCH}

absorption of SAMs, on average $0.28 \mathrm{~mA} \mathrm{~cm}^{-2}$ higher $J_{s c}$ was measured compared to PTAAbased devices. Further studies will cope with generating an understanding of the charge extraction process by the monolayer. We believe that even higher efficiencies can be obtained upon further optimization by means of molecular and compositional engineering, e.g. by introducing active functional groups in the structure of the monolayer.

\section{Supporting Information}

Supporting Information is available from the Wiley Online Library or from the author.

\section{Acknowledgements}

A.M. and A.A.A. contributed equally to this work. A.M. acknowledges funding by the German Academic Exchange Service (DAAD). A.A.A., M.J., and S.A. acknowledge the German Federal Ministry of Education and Research (BMBF) for funding of the Young Investigator Group (grant no. 03SF0540) within the project "Materialforschung für die Energiewende". The authors acknowledge E. Kamarauskas from Vilnius University for measurements of ionization potential and C. Klimm from Helmholtz-Center Berlin for SEM measurements. A.A.A. thanks Nga Phung for her help with impedance spectroscopy.

Received: ((will be filled in by the editorial staff))

Revised: ((will be filled in by the editorial staff)) Published online: ((will be filled in by the editorial staff))

\section{References}

[1] NREL efficiency chart. NREL Effic. chart 2018.

[2] W. S. Yang, B.-W. Park, E. H. Jung, N. J. Jeon, Y. C. Kim, D. U. Lee, S. S. Shin, J. Seo, E. K. Kim, J. H. Noh, S. Il Seok, Science 2017, 356, 1376.

[3] L. Kegelmann, C. M. Wolff, C. Awino, F. Lang, E. L. Unger, L. Korte, T. Dittrich, D. Neher, B. Rech, S. Albrecht, ACS Appl. Mater. Interfaces 2017, 9, 17245.

[4] S.-H. Turren-Cruz, M. Saliba, M. T. Mayer, H. Juárez-Santiesteban, X. Mathew, L. Nienhaus, W. Tress, M. P. Erodici, M.-J. Sher, M. G. Bawendi, M. Grätzel, A. Abate, A. Hagfeldt, J.-P. Correa-Baena, Energy Environ. Sci. 2018, 11, 78.

[5] E. H. Anaraki, A. Kermanpur, L. Steier, K. Domanski, T. Matsui, W. Tress, M. Saliba, 


\section{WILEY-VCH}

A. Abate, M. Grätzel, A. Hagfeldt, J.-P. Correa-Baena, Energy Environ. Sci. 2016, 9 , 3128.

[6] D. Yang, X. Zhou, R. Yang, Z. Yang, W. Yu, X. Wang, C. Li, S. (Frank) Liu, R. P. H. Chang, Energy Environ. Sci. 2016, 9, 3071.

[7] J. Zhao, X. Zheng, Y. Deng, T. Li, Y. Shao, A. Gruverman, J. Shield, J. Huang, Energy Environ. Sci. 2016, 9, 3650.

[8] M. Stolterfoht, C. M. Wolff, Y. Amir, A. Paulke, L. Perdigón-Toro, P. Caprioglio, D. Neher, Energy Environ. Sci. 2017, 10, 1530.

[9] J. H. Heo, H. J. Han, D. Kim, T. K. Ahn, S. H. Im, Energy Environ. Sci. 2015, 8, 1602.

[10] D. Bryant, S. Wheeler, B. C. O’Regan, T. Watson, P. R. F. Barnes, D. Worsley, J. Durrant, J. Phys. Chem. Lett. 2015, 6, 3190.

[11] P. Calado, A. M. Telford, D. Bryant, X. Li, J. Nelson, B. C. O’Regan, P. R. F. Barnes, Nat. Commun. 2016, 7, 13831.

[12] W. Zhou, Z. Wen, P. Gao, Adv. Energy Mater. 2018, 8, 1702512.

[13] K. Jäger, L. Korte, B. Rech, S. Albrecht, Opt. Express 2017, 25, A473.

[14] K. A. Bush, A. F. Palmstrom, Z. J. Yu, M. Boccard, R. Cheacharoen, J. P. Mailoa, D. P. McMeekin, R. L. Z. Hoye, C. D. Bailie, T. Leijtens, I. M. Peters, M. C. Minichetti, N. Rolston, R. Prasanna, S. Sofia, D. Harwood, W. Ma, F. Moghadam, H. J. Snaith, T. Buonassisi, Z. C. Holman, S. F. Bent, M. D. McGehee, Nat. Energy 2017, 2, 17009.

[15] C. Bi, Q. Wang, Y. Shao, Y. Yuan, Z. Xiao, J. Huang, Nat. Commun. 2015, 6, 7747.

[16] O. Malinkiewicz, A. Yella, Y. H. Lee, G. M. Espallargas, M. Graetzel, M. K. Nazeeruddin, H. J. Bolink, Nat. Photonics 2014, 8, 128.

[17] J. T.-W. Wang, Z. Wang, S. Pathak, W. Zhang, D. W. deQuilettes, F. WisniveskyRocca-Rivarola, J. Huang, P. K. Nayak, J. B. Patel, H. A. Mohd Yusof, Y. Vaynzof, R. Zhu, I. Ramirez, J. Zhang, C. Ducati, C. Grovenor, M. B. Johnston, D. S. Ginger, R. J. Nicholas, H. J. Snaith, Energy Environ. Sci. 2016, 9, 2892. 


\section{WILEY-VCH}

[18] P. Docampo, J. M. Ball, M. Darwich, G. E. Eperon, H. J. Snaith, Nat. Commun. 2013, 4, 2761.

[19] C.-G. Wu, C.-H. Chiang, Z.-L. Tseng, M. K. Nazeeruddin, A. Hagfeldt, M. Grätzel, Energy Environ. Sci. 2015, 8, 2725.

[20] W. Chen, Y. Wu, Y. Yue, J. Liu, W. Zhang, X. Yang, H. Chen, E. Bi, I. Ashraful, M. Grätzel, L. Han, Science 2015, 350, 944.

[21] C. Momblona, L. Gil-Escrig, E. Bandiello, E. M. Hutter, M. Sessolo, K. Lederer, J. Blochwitz-Nimoth, H. J. Bolink, Energy Environ. Sci. 2016, 9, 3456.

[22] P. J. Hotchkiss, S. C. Jones, S. A. Paniagua, A. Sharma, B. Kippelen, N. R. Armstrong, S. R. Marder, Acc. Chem. Res. 2012, 45, 337.

[23] S. A. Paniagua, A. J. Giordano, O. L. Smith, S. Barlow, H. Li, N. R. Armstrong, J. E. Pemberton, J. L. Brédas, D. Ginger, S. R. Marder, Chem. Rev. 2016, 116, 7117-7158.

[24] P. B. Paramonov, S. A. Paniagua, P. J. Hotchkiss, S. C. Jones, N. R. Armstrong, S. R. Marder, J.-L. Brédas, Chem. Mater. 2008, 20, 5131-5133.

[25] S. A. Paniagua, P. J. Hotchkiss, S. C. Jones, S. R. Marder, A. Mudalige, F. S. Marrikar, J. E. Pemberton, N. R. Armstrong, J. Phys. Chem. C 2008, 112, 7809-7817.

[26] S. A. Paniagua, E. L. Li, S. R. Marder, Phys. Chem. Chem. Phys. 2014, 16, 2874.

[27] Peng Wang, Cédric Klein, Jacques-E. Moser, Robin Humphry-Baker, Ngoc-Le CeveyHa, Raphael Charvet, Pascal Comte, A. Shaik M. Zakeeruddin, M. Grätzel, J. Phys. Chem. B 2004, 108, 17553.

[28] R. Cinnsealach, G. Boschloo, S. Nagaraja Rao, D. Fitzmaurice, Sol. Energy Mater. Sol. Cells 1999, 57, 107.

[29] N. Vlachopoulos, J. Nissfolk, M. Möller, A. Briançon, D. Corr, C. Grave, N. Leyland, R. Mesmer, F. Pichot, M. Ryan, G. Boschloo, A. Hagfeldt, Electrochim. Acta 2008, 53, 4065.

[30] J. A. Bardecker, H. Ma, T. Kim, F. Huang, M. S. Liu, Y.-J. Cheng, G. Ting, A. K.-Y. 


\section{WILEY-VCH}

Jen, Adv. Funct. Mater. 2008, 18, 3964.

[31] B. Gothe, T. de Roo, J. Will, T. Unruh, S. Mecking, M. Halik, Nanoscale 2017, 9, 18584.

[32] M. Novak, A. Ebel, T. Meyer-Friedrichsen, A. Jedaa, B. F. Vieweg, G. Yang, K. Voitchovsky, F. Stellacci, E. Spiecker, A. Hirsch, M. Halik, Nano Lett. 2011, 11, 156.

[33] Y. Hou, S. Scheiner, X. Tang, N. Gasparini, M. Richter, N. Li, P. Schweizer, S. Chen, H. Chen, C. O. R. Quiroz, X. Du, G. J. Matt, A. Osvet, E. Spiecker, R. H. Fink, A. Hirsch, M. Halik, C. J. Brabec, Adv. Mater. Interfaces 2017, 4, 1700007.

[34] Y. Hou, X. Du, S. Scheiner, D. P. McMeekin, Z. Wang, N. Li, M. S. Killian, H. Chen, M. Richter, I. Levchuk, N. Schrenker, E. Spiecker, T. Stubhan, N. A. Luechinger, A. Hirsch, P. Schmuki, H.-P. Steinrück, R. H. Fink, M. Halik, H. J. Snaith, C. J. Brabec, Science 2017, 358, 1192.

[35] P. Topolovsek, F. Lamberti, T. Gatti, A. Cito, J. M. Ball, E. Menna, C. Gadermaier, A. Petrozza, J. Mater. Chem. A 2017, 5, 11882.

[36] X. Lin, A. N. Jumabekov, N. N. Lal, A. R. Pascoe, D. E. Gómez, N. W. Duffy, A. S. R. Chesman, K. Sears, M. Fournier, Y. Zhang, Q. Bao, Y.-B. Cheng, L. Spiccia, U. Bach, Nat. Commun. 2017, 8, 613.

[37] M. Saliba, T. Matsui, J.-Y. Seo, K. Domanski, J.-P. Correa-Baena, M. K. Nazeeruddin, S. M. Zakeeruddin, W. Tress, A. Abate, A. Hagfeldt, M. Grätzel, Energy Environ. Sci. 2016, 9, 1989.

[38] A. Magomedov, S. Paek, P. Gratia, E. Kasparavicius, M. Daskeviciene, E. Kamarauskas, A. Gruodis, V. Jankauskas, K. Kantminiene, K. T. Cho, K. Rakstys, T. Malinauskas, V. Getautis, M. K. Nazeeruddin, Adv. Funct. Mater. 2018, 1704351.

[39] P. Gratia, A. Magomedov, T. Malinauskas, M. Daskeviciene, A. Abate, S. Ahmad, M. Grätzel, V. Getautis, M. K. Nazeeruddin, Angew. Chemie Int. Ed. 2015, 54, 11409.

[40] S. Do Sung, M. S. Kang, I. T. Choi, H. M. Kim, H. Kim, M. Hong, H. K. Kim, W. I. 


\section{WILEY-VCH}

Lee, Chem. Commun. 2014, 50, 14161.

[41] A. Khassanov, H.-G. Steinrück, T. Schmaltz, A. Magerl, M. Halik, Acc. Chem. Res. 2015, 48, 1901.

[42] A. Rumpel, M. Novak, J. Walter, B. Braunschweig, M. Halik, W. Peukert, Langmuir 2011, 27, 15016.

[43] K. Jo, H. Yang, J. Electroanal. Chem. 2014, 712, 8.

[44] N. Metoki, L. Liu, E. Beilis, N. Eliaz, D. Mandler, Langmuir 2014, 30, 6791.

[45] S. Schneider, M. Füser, M. Bolte, A. Terfort, Electrochim. Acta 2017, 246, 853.

[46] O. I. Negru, M. Grigoras, J. Polym. Res. 2015, 22, 637.

[47] A. Botta, S. Pragliola, V. Venditto, A. Rubino, S. Aprano, A. De Girolamo Del Mauro, M. Grazia Maglione, C. Minarini, Polym. Compos. 2015, 36, 1110.

[48] O. Abbas, G. Compère, Y. Larondelle, D. Pompeu, H. Rogez, V. Baeten, Vib. Spectrosc. 2017, 92, 111.

[49] S. Ye, M. Osawa, Chem. Lett. 2009, 38, 386.

[50] Y. R. Shen, Nature 1989, 337, 519.

[51] Z. Tang, S. Uchida, T. Bessho, T. Kinoshita, H. Wang, F. Awai, R. Jono, M. M. Maitani, J. Nakazaki, T. Kubo, H. Segawa, Nano Energy 2018, 45, 184.

[52] C. Wang, C. Zhang, S. Wang, G. Liu, H. Xia, S. Tong, J. He, D. Niu, C. Zhou, K. Ding, Y. Gao, J. Yang, Sol. RRL 2018, 2, 1700209.

[53] M. Deepa, M. Salado, L. Calio, S. Kazim, S. M. Shivaprasad, S. Ahmad, Phys. Chem. Chem. Phys. 2017, 19, 4069.

[54] T. Matsui, I. Petrikyte, T. Malinauskas, K. Domanski, M. Daskeviciene, M. Steponaitis, P. Gratia, W. Tress, J.-P. Correa-Baena, A. Abate, A. Hagfeldt, M. Grätzel, M. K. Nazeeruddin, V. Getautis, M. Saliba, ChemSusChem 2016, 9, 2567.

[55] W. Zhou, Z. Wen, P. Gao, Adv. Energy Mater. 2018, 8, 1702512.

[56] C. Bi, Q. Wang, Y. Shao, Y. Yuan, Z. Xiao, J. Huang, Nat. Commun. 2015, 6, 7747. 


\section{WILEY-VCH}

[57] D. Moia, A. Szumska, V. Vaissier, M. Planells, N. Robertson, B. C. O’Regan, J.

Nelson, P. R. F. Barnes, J. Am. Chem. Soc. 2016, 138, 13197-13206.

[58] M. D. Losego, J. T. Guske, A. Efremenko, J.-P. Maria, S. Franzen, Langmuir 2011, 27, 11883.

Scheme 1. A) Synthesis of the phosphonic acid functionalized carbazole derivative V1036; B) Chemical structure of $\mathrm{C} 4$, which was used in this study for the formation of mixed SAMs A)

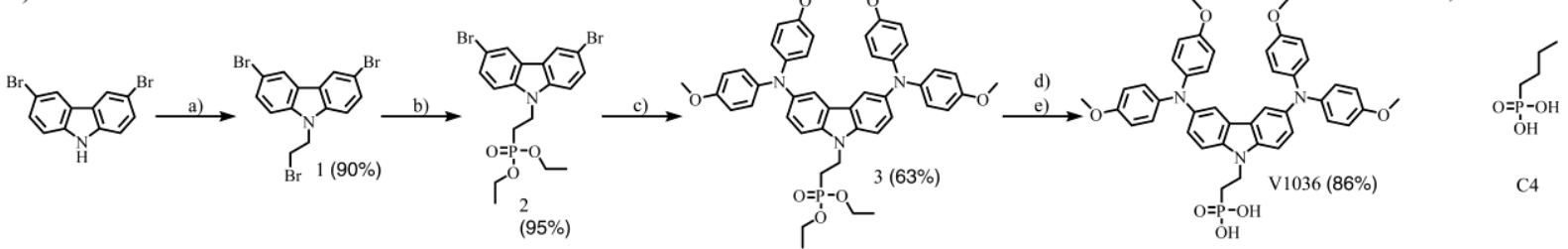

a) 1,2-dibromoethane (6.5 ml/equiv.), $\mathrm{TBABr}(0.3$ equiv.), $50 \% \mathrm{KOH}$ aqueous solution (15 equiv.), $72 \mathrm{~h}, 60^{\circ} \mathrm{C}$; ${ }^{\text {b) }}$ triethylphosphite $(3.6 \mathrm{ml} /$ equiv. $), 18 \mathrm{~h}, 165^{\circ} \mathrm{C}$; ${ }^{\text {c) }} 4,4^{\prime}$ dimethoxydiphenylamine ( 3 equiv.), $\mathrm{Pd}(\mathrm{OAc})_{2}$ ( 0.3 equiv.), $\mathrm{P}(t-\mathrm{Bu})_{3} \cdot \mathrm{BF}_{3}(0.6$ equiv.), $\mathrm{NaO} t$ $\mathrm{Bu}$ (3 equiv.), anhydrous toluene (24.5 ml/equiv.), Ar, $5 \mathrm{~h}$, reflux; ${ }^{\mathrm{d})} \mathrm{BrSi}\left(\mathrm{CH}_{3}\right)_{3}$ (10 equiv.), anhydrous dioxane (29.4 ml/equiv.), Ar, $24 \mathrm{~h}, 25^{\circ} \mathrm{C}$; ${ }^{\text {e) }} \mathrm{MeOH}$ (19.6 ml/equiv.), $\mathrm{H}_{2} \mathrm{O}$ (19.6 ml/equiv.), 15 h, r.t. 


\section{WILEY-VCH}

A)

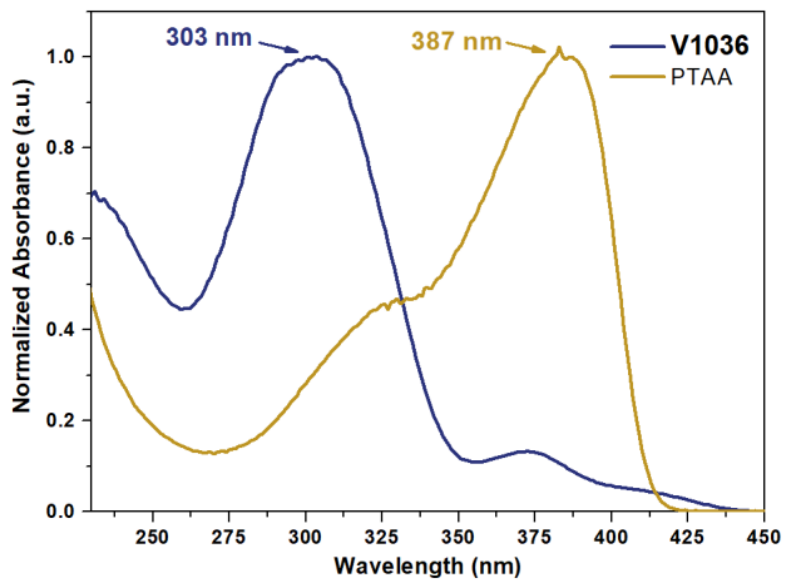

B)

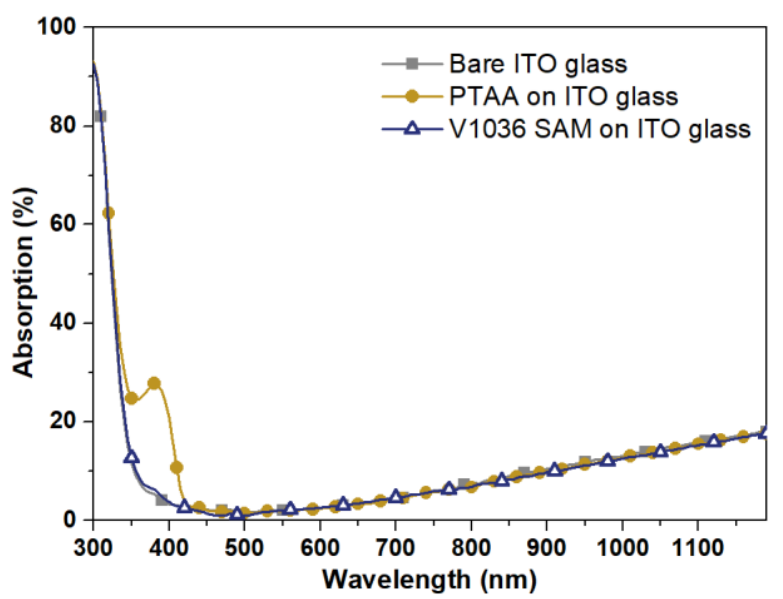

Figure 1. A) UV/vis absorption spectra for $10^{-4} \mathrm{M}$ THF solution of V1036 and PTAA; B) UV/vis absorption spectra of the bare ITO substrate, ITO with PTAA, and ITO with $100 \%$ V1036 SAM.

A)

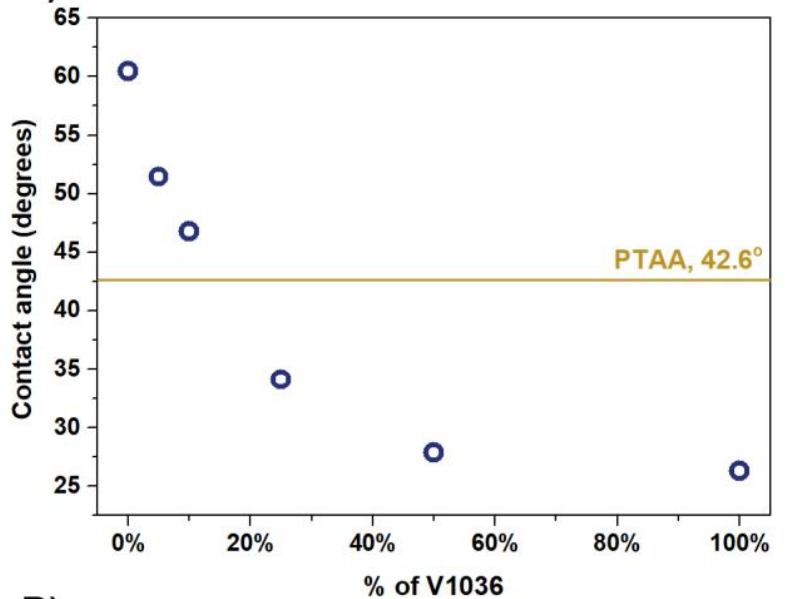

B)
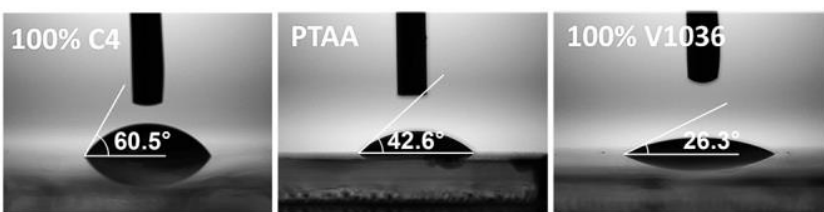


\section{WILEY-VCH}

Figure 2. A) Contact angle dependence on the percentage of the V1036 in the SAM composition; B) Equilibrium contact angle of perovskite solution on 100\% C4 SAM; PTAA; $100 \%$ V1036 SAM.
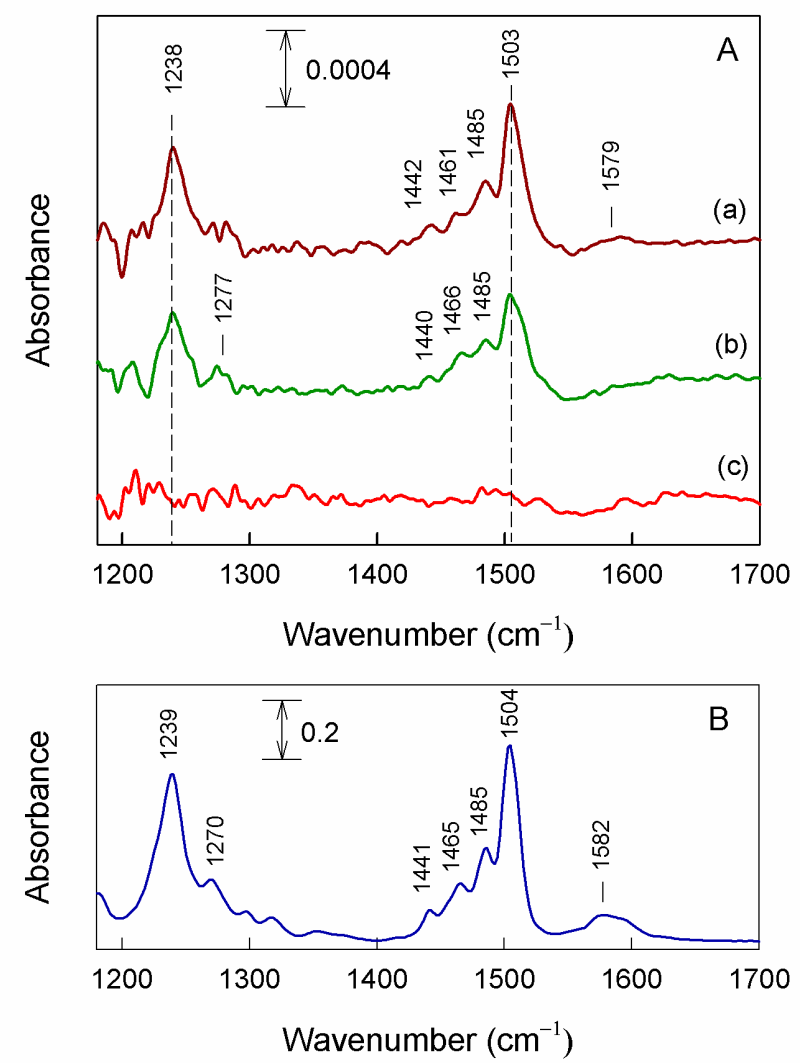

Figure 3. A) FTIR absorbance spectra of monolayers on ITO substrates prepared from (a) $1 \mathrm{mM}$ solution of V1036, (b) $1 \mathrm{mM}$ of mixed solution V1036:C4 (1:9), and (c) $1 \mathrm{mM}$ solution of C4. B) FTIR spectrum of bulk V1036 in $\mathrm{KBr}$ tablet.
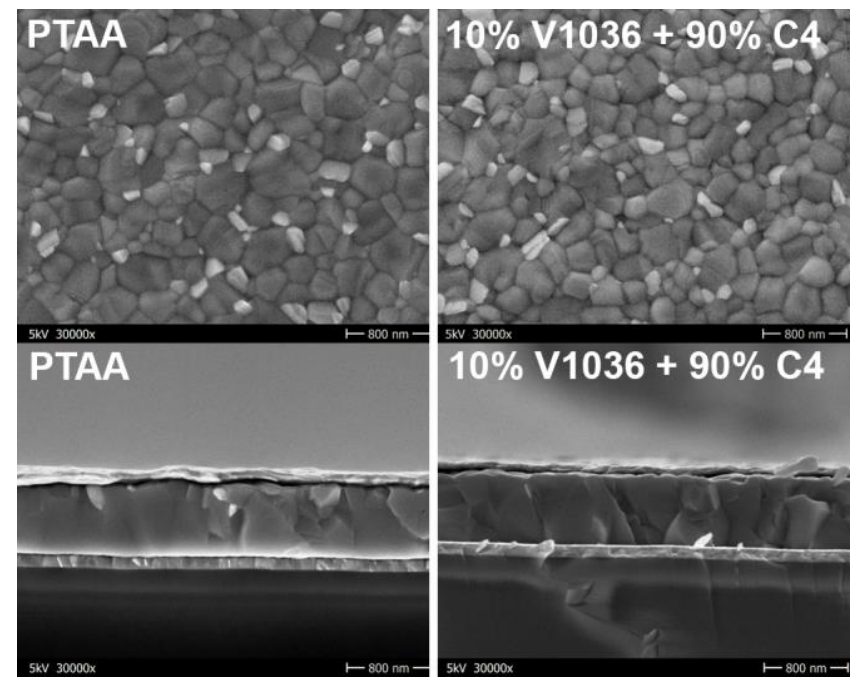

Figure 4. Top-view (top) and cross-sectional (bottom) SEM micrographs of perovskite film, deposited on PTAA and SAM-coated substrates. 


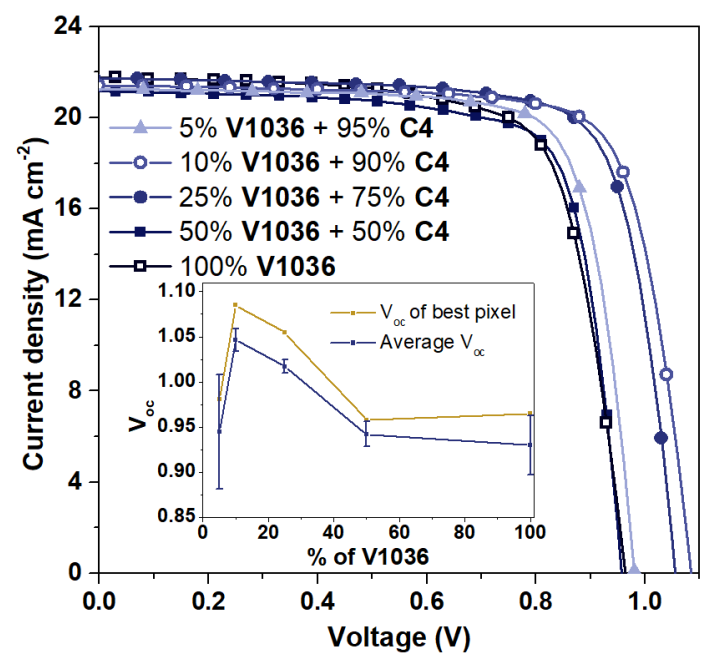

Figure 5. J-V characteristics of the best performing PSCs with mixed SA-HTMs. Inset: Average and best $V_{o c}$ values obtained for different portions of $\mathbf{V 1 0 3 6}$ in the adsorption solution. Error bars are showing the standard error.

A)
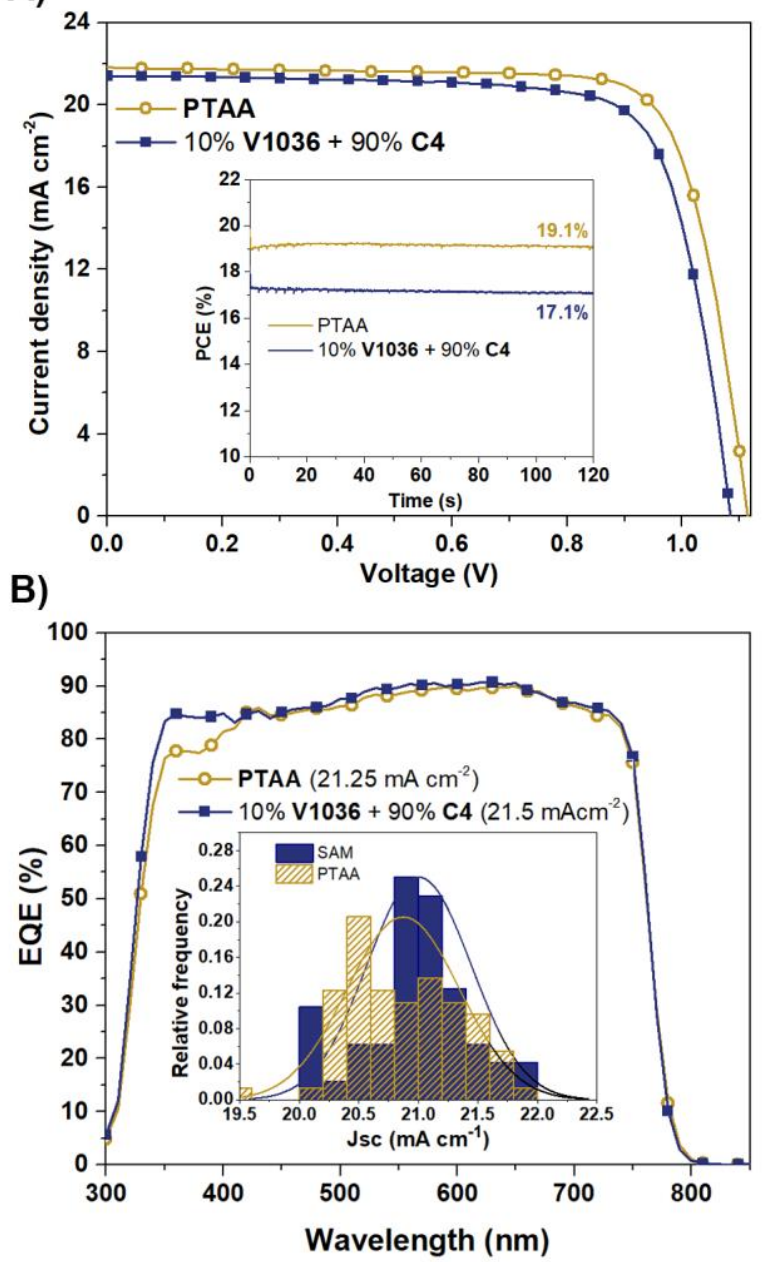

Figure 6. A) J-V characteristics of the best performing PSCs with $10 \%$ V1036 $90 \%$ C4 SAM and PTAA HTMs. The inset shows maximum power point (MPP) track of the best devices. B) EQE spectra of representative PTAA and mixed SA-HTM devices. The current values in parentheses are integrated $J_{s c}$ values from the shown EQE spectra and the inset shows the statistical distribution of $J_{s c}$ for both device types. 


\section{WILEY-VCH}

Table 1. $I_{p}\left(W_{f}\right.$ for ITO), $E_{g}{ }^{o p t}$, and $E A$ values of the investigated substrates

\begin{tabular}{llll}
\hline Material & $I_{p}\left(W_{f}\right.$ for ITO), $\mathrm{eV}$ & $E_{g^{o p t}}, \mathrm{eV}^{a}$ & $E A, \mathrm{eV}^{b}$ \\
\hline bulk V1036 & 5.04 & 2.75 & 2.29 \\
$100 \%$ V1036 SAM & 4.98 & $2.75^{b}$ & 2.23 \\
$10 \%$ V1036 90\% C4 SAM & 5.09 & $2.75^{b}$ & 2.34 \\
PTAA & 5.18 & 2.96 & 2.22 \\
ITO & $4.6^{[3]}$ & - & -
\end{tabular}

${ }^{a}$ Optical band gap $\left(E_{g}{ }^{\text {opt }}\right)$ estimated from the edge of absorption spectra ${ }^{b}$ For SAMs same $E_{g}{ }^{\text {opt }}$ value as for bulk V1036 was used ${ }^{c} E A$ calculated using the equation $E A=I_{p}-E_{g}{ }^{\text {opt }}$. 


\section{WILEY-VCH}

Table 2. Average PSC performance parameters for different SA-HTM compositions

\begin{tabular}{lllll}
\hline SA-HTM & $J_{s c}, \mathrm{~mA} \cdot \mathrm{cm}^{-2}$ & $V_{o c}, \mathrm{~V}$ & $F F, \%$ & PCE, \% \\
\hline $5 \%$ V1036 95\% C4 & $21.08 \pm 0.27(21.26)$ & $0.95 \pm 0.06(0.98)$ & $65.80 \pm 2.11(77.12)$ & $13.05 \pm 0.90(16.07)$ \\
$10 \%$ V1036 90\% C4 & $21.19 \pm 0.10(21.41)$ & $1.05 \pm 0.01(1.09)$ & $70.87 \pm 1.76(76.49)$ & $15.78 \pm 0.55(17.77)$ \\
$25 \%$ V1036 75\% C4 & $21.27 \pm 0.19(21.74)$ & $1.02 \pm 0.01(1.06)$ & $71.22 \pm 1.56(76.11)$ & $15.43 \pm 0.48(17.45)$ \\
$50 \%$ V1036 50\% C4 & $20.91 \pm 0.08(21.16)$ & $0.94 \pm 0.01(0.96)$ & $67.17 \pm 2.20(76.00)$ & $13.24 \pm 0.51(15.40)$ \\
$100 \%$ V1036 & $21.22 \pm 0.28(21.77)$ & $0.93 \pm 0.03(0.96)$ & $66.48 \pm 2.12(72.81)$ & $13.16 \pm 0.83(15.29)$ \\
\hline
\end{tabular}

${ }^{a}$ Data was extracted from J-V scans, including the standard errors and performance parameters of the best devices (in brackets). The statistics is based on 9-15 cells on different substrates for each SA-HTM composition.

Table 3. Average PSCs performance parameters with 10\% V1036 90\% C4 and PTAA HTMs

\begin{tabular}{lllll}
\hline HTM & $J_{s c}, \mathrm{~mA}^{\cdot \mathrm{cm}^{-2}}$ & $V_{o c}, \mathrm{~V}$ & $F F, \%$ & PCE, \% \\
\hline PTAA & $20.87 \pm 0.06(21.847)$ & $1.09 \pm 0.002(1.13)$ & $77.82 \pm 0.28(80.98)$ & $17.69 \pm 0.08(19.23)$ \\
$10 \% \mathbf{V 1 0 3 6} 90 \% \mathbf{C 4}$ & $21.01 \pm 0.06(21.87)$ & $1.00 \pm 0.006(1.09)$ & $78.33 \pm 0.46(80.98)$ & $16.46 \pm 0.15(17.77)$ \\
\hline
\end{tabular}

${ }^{a}$ Data, extracted from J-V scans, including the standard errors and the best performance parameters (in brackets). The statistics is based on 41 and 68 cells from several batches for $10 \%$ V1036 $90 \%$ C4 and PTAA respectively. 


\section{WILEY-VCH}

A novel concept for the formation of the hole selective layer in efficient perovskite solar cells is presented. Carbazole-based material was synthesized and used for the formation of a self-assembled monolayer on top of the indium tin oxide transparent conductive substrate.

Power conversion efficiency as high as $17.8 \%$ was achieved.

Self-assembled monolayers, hole transporting materials, perovskite solar cells

A. Magomedov, A. Al-Ashouri, E. Kasparavičius, S. Strazdaite, G. Niaura, M. Jošt, T. Malinauskas, S. Albrecht*, V. Getautis*

Self-Assembled Hole Transporting Monolayer for Perovskite Solar Cells 


\section{WILEY-VCH}

Copyright WILEY-VCH Verlag GmbH \& Co. KGaA, 69469 Weinheim, Germany, 2016.

\section{Supporting Information}

\section{Self-Assembled Hole Transporting Monolayer for Perovskite Solar Cells}

Artiom Magomedov, Amran Al-Ashouri, Ernestas Kasparavičius, Simona Strazdaite, Gediminas Niaura, Marko Jošt, Tadas Malinauskas, Steve Albrecht* and Vytautas Getautis*

\section{General methods}

Chemicals, unless stated otherwise, were purchased from Sigma-Aldrich and TCI Europe and used as received without further purification. The ${ }^{1} \mathrm{H}$ and ${ }^{13} \mathrm{C}$ NMR spectra were taken on Bruker Avance III (400 MHz) spectrometer at RT. All the data are given as chemical shifts in $\delta(\mathrm{ppm})$. The course of the reactions products was monitored by TLC on ALUGRAM SIL G/UV254 plates and developed with UV light. Silica gel (grade 9385, 230-400 mesh, 60 A, Aldrich) was used for column chromatography. Elemental analysis was performed with an Exeter Analytical CE-440 elemental analyser, Model 440 C/H/N/. Electrothermal MELTEMP capillary melting point apparatus was used for determination of melting points. UV/Vis spectra were recorded on a PerkinElmer Lambda 35 spectrometer.

\section{Formation of the SAMs}

V1036, as well as mixed V1036 and $n$-butylphosphonic acid (C4) SAMs were formed by immersing UV-ozone treated ITO substrates into $1 \mathrm{mM}$ solution of phosphonic acid molecules, dissolved in isopropanol, for $20 \mathrm{~h}$, followed by annealing at $100{ }^{\circ} \mathrm{C}$ for $1 \mathrm{~h}$ and subsequent washing with isopropanol and chlorobenzene. To exclude any possible negative impact of atmospheric oxygen all procedures were done in a nitrogen-filled glovebox. Used notation: e.g. $10 \%$ V1036 $90 \%$ C4 SAM means that monolayer was formed using a solution 


\section{WILEY-VCH}

containing $0.1 \mathrm{mM}$ of $\mathbf{V 1 0 3 6}$ and $0.9 \mathrm{mM}$ of $\mathbf{C 4}$. Sometimes a shortened notation was used, showing only percentage p of V1036 in the solution (implying a percentage of 1-p for C4).

\section{TGA}

Thermogravimetric analysis (TGA) was performed on a Q50 thermogravimetric analyser (TA Instruments) at a scan rate of $10 \mathrm{~K} \mathrm{~min}^{-1}$ under nitrogen atmosphere.

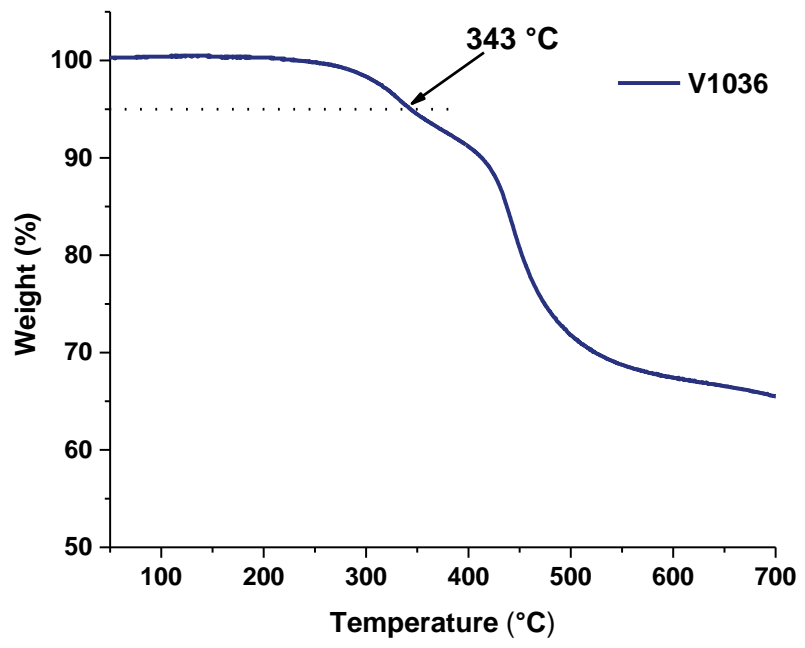

Figure S1. TGA heating curve V1036. Heating rate $10^{\circ} \mathrm{C} \mathrm{min}^{-1}$.

\section{FTIR measurements}

For the FTIR and VSFG measurements, $30 \mathrm{~nm}$ ITO was deposited on $625 \mu \mathrm{m}$ thick Silicon substrates with DC magnetron sputter deposition in a Roth \& Rau sputter tool at room temperature. SAMs were formed on these substrates according to the above mentioned procedure.

FTIR spectra of monolayers were recorded in transmission mode by using FTIR spectrometer Vertex 80v (Bruker, Inc., Germany), equipped with a liquid-nitrogen cooled MCT narrow band detector. Spectra were acquired from 512 interferogram scans with $4 \mathrm{~cm}^{-1}$ resolution; final spectrum was obtained by averaging two spectra. A blank Si substrate with $30 \mathrm{~nm}$ thick 


\section{WILEY-VCH}

ITO layer was used as a reference sample. The sample chamber and the spectrometer were evacuated during the measurements. Spectra were corrected by polynomial function background subtraction. No smoothing procedures were applied to the experimental data. Parameters of the bands were determined by fitting the experimental contour to GaussianLorentzian shape components using GRAMS/AI 8.0 (Thermo Electron Corp.) software. The infrared spectrum of bulk V1036 sample was recorded in transmission mode on an ALPHA FTIR spectrometer (Bruker, Inc., Germany), equipped with a room temperature detector DLATGS. The spectral resolution was set at $4 \mathrm{~cm}^{-1}$. The spectrum was acquired from 124 interferogram scans. The sample solution was dispersed in a $\mathrm{KBr}$ tablet.

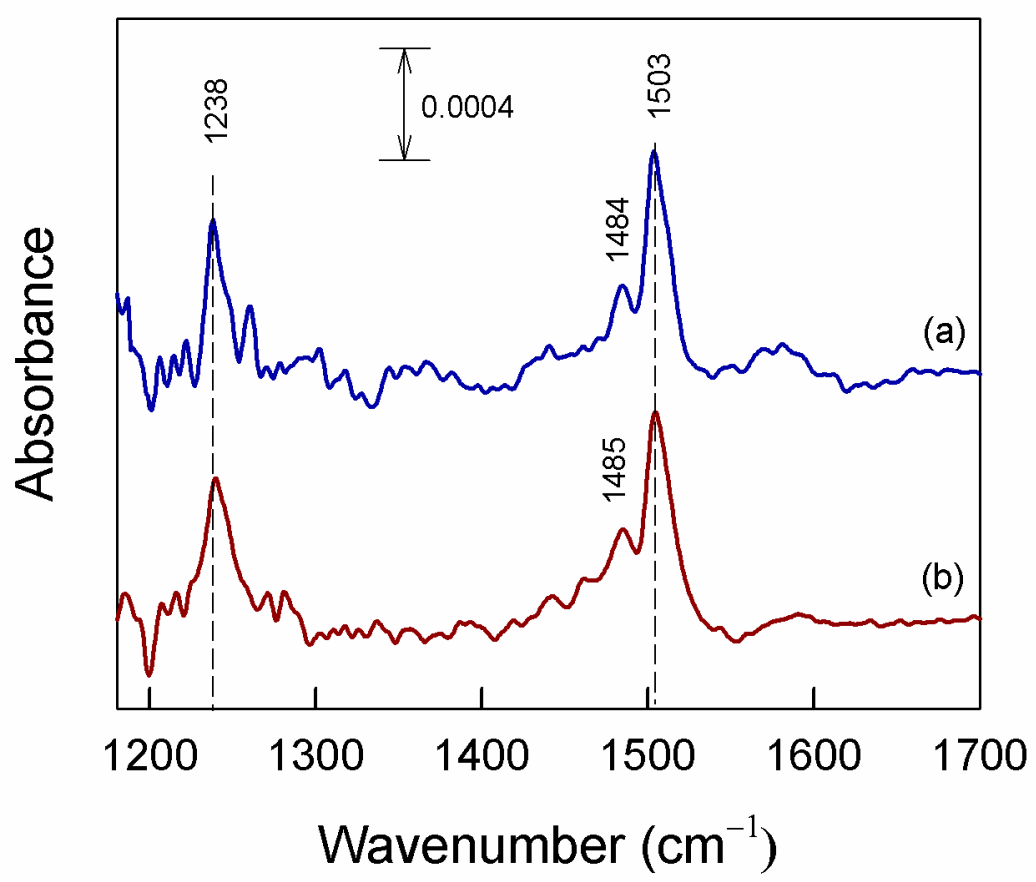

Figure S2. FTIR absorbance spectra of V1036 monolayers prepared from (a) $0.1 \mathrm{mM}$ and (b) $1 \mathrm{mM}$ adsorption solutions. 


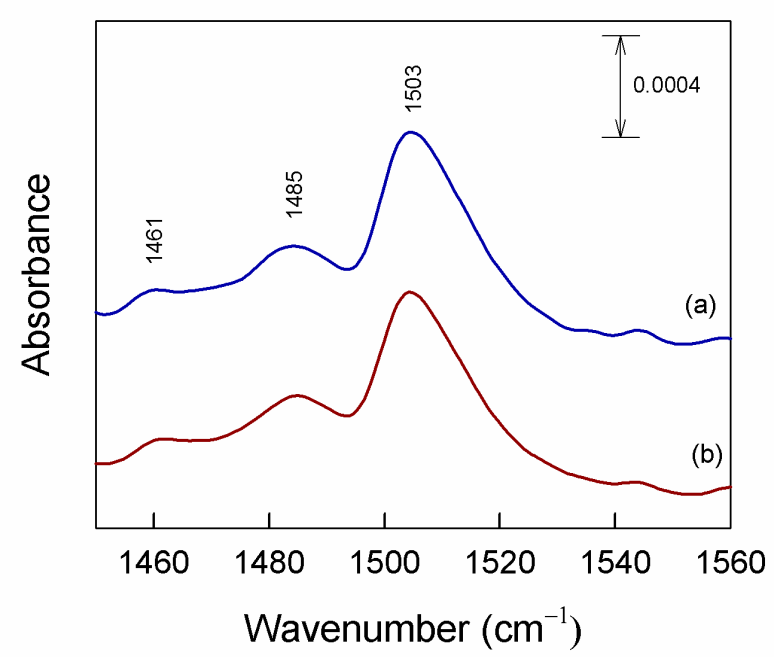

Figure S3. FTIR absorbance spectra of $100 \%$ V1036 monolayer in the spectral range of 1503 $\mathrm{cm}^{-1}$ band recorded (a) initially and (b) after 25 days.

\section{Vibrational Sum frequency generation (VSFG) measurements}

VSFG spectra were recorded using a commercially available VSFG system (Ekspla PL2143A20). The method was described in detail in previous work. ${ }^{[1]}$ In short, a Nd:YAG laser generates pulses at $1064 \mathrm{~nm}$ with a pulse length of $\sim 28 \mathrm{ps}$ and $20 \mathrm{kHz}$ repetition rate. Part of the laser output is used to pump optical parametric generator (EKSPLA PG401VIR/DFG) to produce infrared pulses $\left(\omega_{\mathrm{IR}}\right)$, which can be tuned in the range between $1000 \mathrm{~cm}^{-1}$ and $4000 \mathrm{~cm}^{-1}$ with typical energies of $60-200 \mu \mathrm{J}$, respectively. The second harmonic of the laser output $(532 \mathrm{~nm})$ is used as a visible beam ( $\left.\omega_{\mathrm{VIS}}\right)$ for sum-frequency generation $\left(\omega_{\mathrm{SF}}\right)$. Sum-frequency is generated when infrared and visible pulses overlap in time and space on the sample surface. All spectra in this work were recorded with a polarization combination $\operatorname{ssp}(\mathrm{s}-\mathrm{SFG}, \mathrm{s}-\mathrm{VIS}, \mathrm{p}$ - IR). The intensity of the visible beam was attenuated to avoid damage of the samples $(\sim 30 \mu \mathrm{J})$. The generated sum-frequency light is filtered with a monochromator and detected with a photomultiplier tube (PMT).

The measured VSFG intensity is proportional to

$I_{V S F G} \propto\left|A_{N R} e^{i \phi}+\sum_{q} \frac{A_{R q}}{\omega_{I R}-\omega_{q}+i \Gamma_{q}}\right|^{2}$, 


\section{WILEY-VCH}

where ${ }^{A_{N R}}$ is the non-resonant amplitude, ${ }^{A}{ }_{R q}$ is the resonant amplitude of the $q$-th vibration, $\phi$ is the phase between resonant and non-resonant contributions. $\omega_{q}$ and $\Gamma_{q}$ are frequency and width of the $q$-th vibration, respectively. 

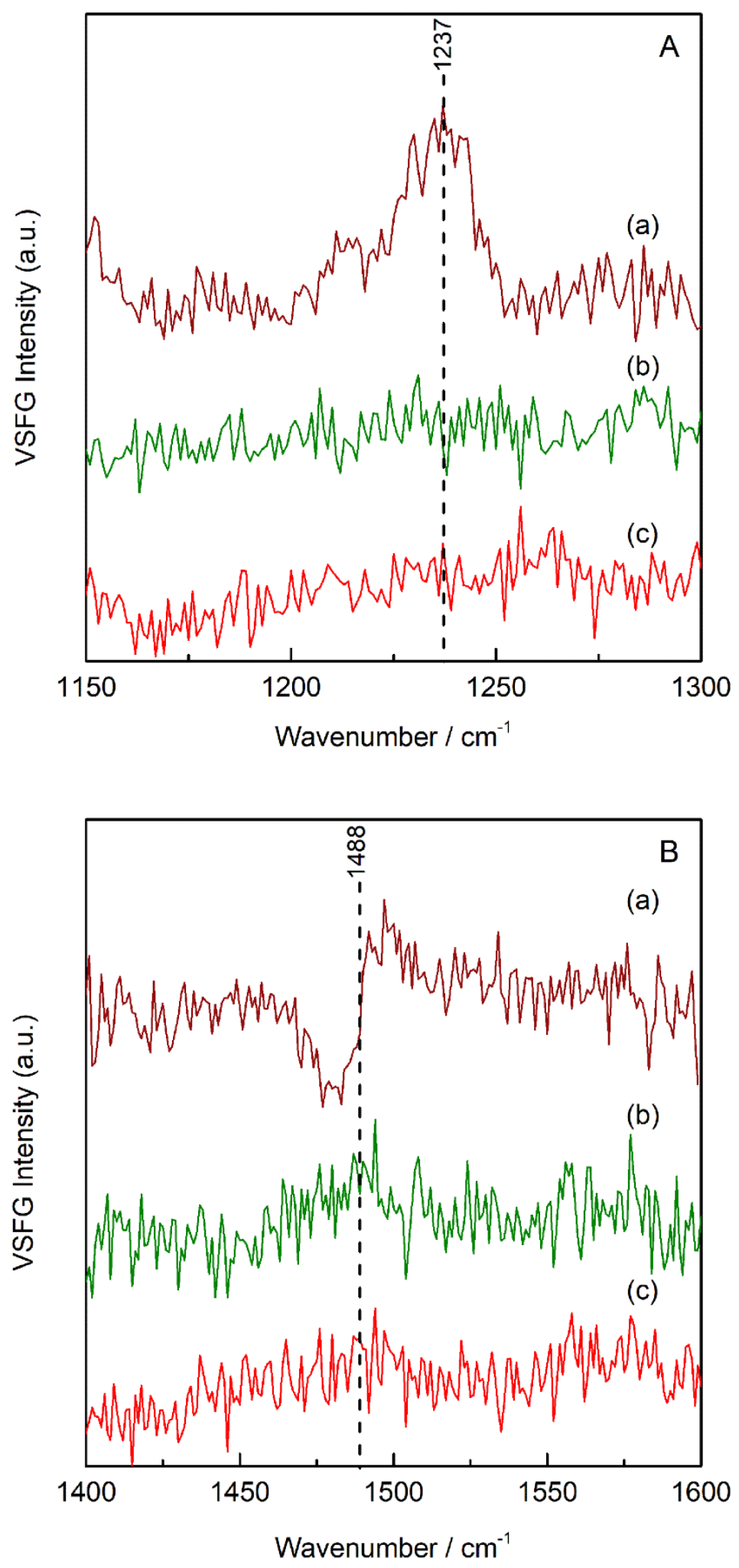

Figure S4. A) VSFG spectra of monolayers on Si/ITO substrate prepared from (a) $1 \mathrm{mM}$ solution of V1036, (b) $1 \mathrm{mM}$ of mixed solution V1036:C4 (1:9), and (c) $1 \mathrm{mM}$ solution of $\mathbf{C 4}$ in the spectral region $1150-1300 \mathrm{~cm}^{-1}$ and $\mathrm{B}$ ) in the spectral region $1400-1600 \mathrm{~cm}^{-1}$. 


\section{WILEY-VCH}

\section{Contact angle}

Contact angle measurements were performed with a Kruss Drop Shape Analysis System DSA25.

Table S1. Values of the equilibrium contact angles for various substrates.

\begin{tabular}{|l|l|}
\hline Substrate & Contact angle, degrees \\
\hline PTAA & 42.59 \\
\hline ITO & 50.02 \\
\hline $100 \% \mathbf{C 4}$ & 60.47 \\
\hline $5 \%$ V1036 95\% C4 & 51.43 \\
\hline $10 \%$ V1036 90\% C4 & 46.75 \\
\hline $25 \% \mathbf{V 1 0 3 6} 75 \% \mathbf{C 4}$ & 34.1 \\
\hline $50 \%$ V1036 50\% C4 & 27.84 \\
\hline $100 \%$ V1036 & 26.28 \\
\hline
\end{tabular}

\section{Ionization potential measurements}

The solid state ionization potential $\left(I_{\mathrm{p}}\right)$ of the V1036, PTAA on ITO, and SA-HTMs on ITO was measured by the electron photoemission in air method. ${ }^{[2-4]}$ The sample for the ionization potential measurement of bulk V1036 was prepared by dissolving the material in THF and coating it on an Al plate, pre-coated with a $\sim 0.5 \mu \mathrm{m}$ thick methylmethacrylate and methacrylic acid copolymer adhesive layer. The thickness of the layer was $\sim 0.5-1 \mu \mathrm{m}$. PTAA layer on ITO was formed by spin-coating, in a similar manner to the procedure used for the PSC formation. SA-HTMs were formed by the above mentioned procedure.

Usually, photoemission experiments are carried out in vacuum and high vacuum is one of the main requirements for these measurements. If the vacuum is not high enough the sample surface oxidation and gas adsorption are influencing the measurement results. In our case, however, the organic materials investigated are stable enough towards oxygen, so that the measurements could be carried out in air. The samples were illuminated with monochromatic 


\section{WILEY-VCH}

light from a quartz monochromator with a deuterium lamp. The power of the incident light beam was $(2-5) \cdot 10^{-8} \mathrm{~W}$. A negative voltage of $-300 \mathrm{~V}$ was supplied to the sample substrate with respect to the counter electrode, which contained a $4.5 \times 15 \mathrm{~mm}^{2}$ slit for illumination and was placed at $8 \mathrm{~mm}$ distance from the sample surface. The counter-electrode was connected to the input of the BK2-16 type electrometer, working in the open input regime, for the photocurrent measurement. The $10^{-15}-10^{-12}$ A strong photocurrent was flowing in the circuit under illumination. The photocurrent $I$ is strongly dependent on the incident light photon energy hv. The $I^{0.5}=f(h v)$ dependence was plotted. Usually the dependence of the photocurrent on incident light quanta energy is well described by a linear relationship between $I^{0.5}$ and $h v$ near the threshold. The linear part of this dependence was extrapolated to the hv axis and $I_{\mathrm{p}}$ value was determined as the photon energy at the interception point.

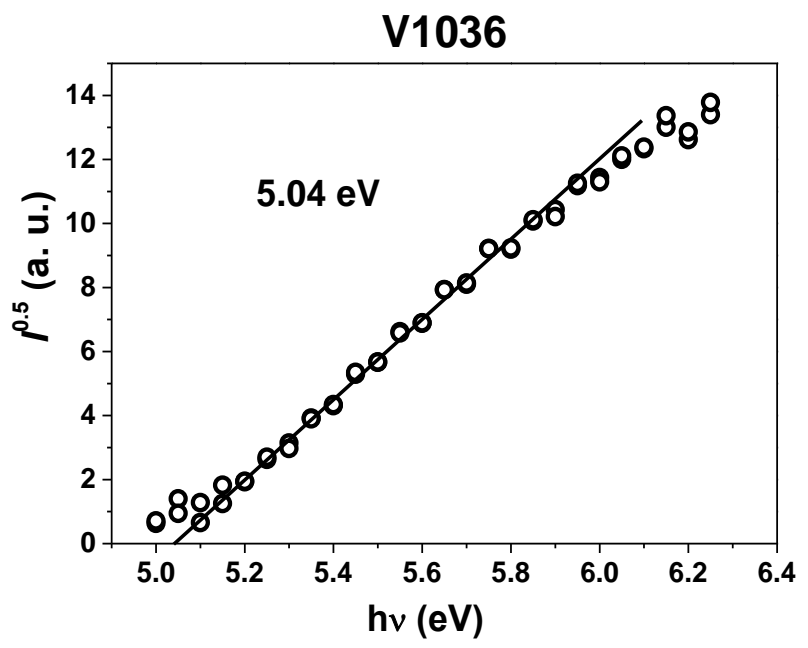

Figure S5. Photoemission in air spectra of the bulk V1036. 


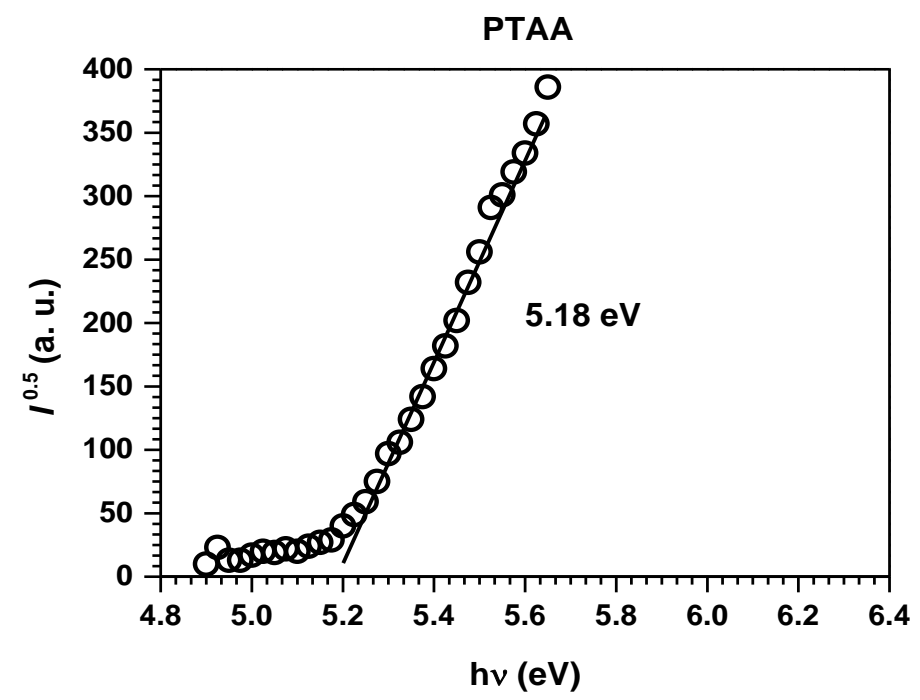

Figure S6. Photoemission in air spectra of the PTAA film on ITO.

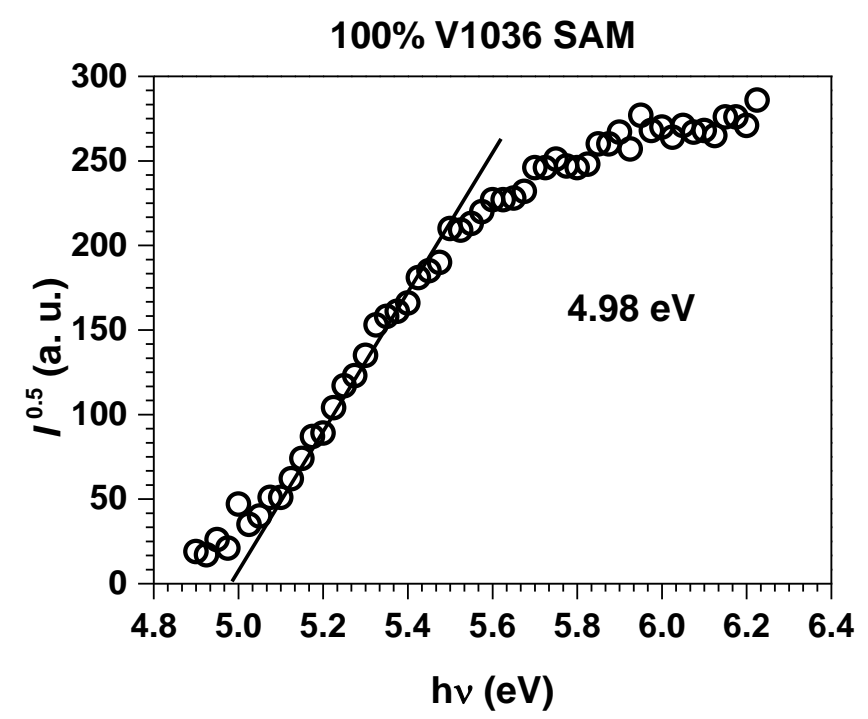

Figure S7. Photoemission in air spectra of the $100 \%$ V1036 SAM. 


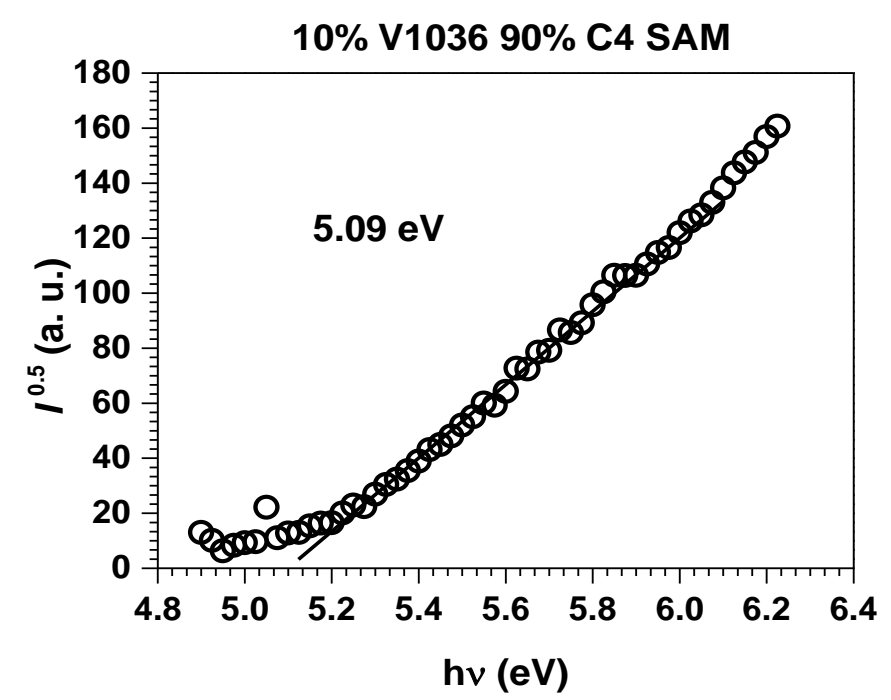

Figure S8. Photoemission in air spectra of the $10 \%$ V1036 90\% C4 SAM.

Table S2. $I_{p}$ values for various substrates.

\begin{tabular}{|l|l|l|l|l|l|}
\hline Substrate & $5 \% \mathbf{V 1 0 3 6}$ & $10 \% \mathbf{V 1 0 3 6}$ & $25 \% \mathbf{V 1 0 3 6}$ & $50 \% \mathbf{V 1 0 3 6}$ & $100 \%$ \\
& $95 \% \mathbf{C 4}$ & $90 \% \mathbf{C 4}$ & $75 \% \mathbf{C 4}$ & $50 \% \mathbf{C 4}$ & $\mathbf{V 1 0 3 6}$ \\
\hline$I_{p}, \mathrm{eV}$ & 5.01 & 5.09 & 5.06 & 5.07 & 4.98 \\
\hline
\end{tabular}

\section{Device fabrication}

Patterned indium tin oxide (ITO) glass substrates $\left(25 \times 25 \mathrm{~mm}, 15 \Omega \mathrm{sq}^{-1}\right.$, patterned by Automatic Research $\mathrm{GmbH}$ ) were cleaned sequentially for 15 min with Mucasol 2\% solution in water (Schülke), Acetone, and Isopropanol in an ultrasonic bath. After that, directly before HTM deposition, substrates were treated in an UV-ozone cleaner for $15 \mathrm{~min}$.

All subsequent procedures were done in a nitrogen-filled glovebox.

SA-HTMs were deposited as specified above.

For the PTAA control devices, PTAA (Sigma Aldrich) was spin-coated from a $2 \mathrm{mg} \mathrm{ml}^{-1}$ solution in anhydrous toluene at $4000 \mathrm{rpm}$ (5 s acceleration) for $30 \mathrm{~s}$ and annealed on a hot plate at $100^{\circ} \mathrm{C}$ for $10 \mathrm{~min}$.

Triple-cation $\mathrm{Cs}_{0.05}\left(\mathrm{MA}_{0.17} \mathrm{FA}_{0.83}\right)_{0.95} \mathrm{~Pb}\left(\mathrm{I}_{0.83} \mathrm{Br}_{0.17}\right)_{3}$ perovskite film was formed according to a slightly modified previously reported procedure. ${ }^{[5]}$ First, $\mathrm{PbBr}_{2}$ and $\mathrm{PbI}_{2}$ were dissolved in a 


\section{WILEY-VCH}

mixture of anhydrous DMF:DMSO (4:1 volume ratio), to a nominal concentration of $1.5 \mathrm{M}$, by shaking overnight at $60^{\circ} \mathrm{C}$. Next, the $\mathrm{PbBr}_{2}$ and $\mathrm{PbI}_{2}$ stock solutions were added to $\mathrm{MABr}$ and FAI powders respectively, to obtain $\mathrm{MAPbBr}_{3}$ and $\mathrm{FAPbI}_{3}$ solutions with a final concentration of $1.24 \mathrm{M}$. The molar ratio between lead and the respective cations was 1.09:1.00 (9\% lead excess) for both solutions. $\mathrm{MAPbBr}_{3}$ and $\mathrm{FAPbI}_{3}$ solutions were then mixed in a 1:5 volume ratio. Finally, the Cesium cation was added from a 1.5 M CsI solution in DMSO in a 5:95 volume ratio. This final Perovskite solution was slightly diluted by adding DMF:DMSO (4:1) in a 5:95 volume ratio for substrates with suboptimal wettability properties. The Perovskite solution was deposited on top of the HTM layer by spin-coating using the following program: $4000 \mathrm{rpm}$ (5 s acceleration) for $35 \mathrm{~s}$ (total time - $40 \mathrm{~s}$ ). After $25 \mathrm{~s}, 500 \mu \mathrm{l}$ of Ethyl Acetate was poured on the spinning substrate. After the spin-coating program, the perovskite-coated sample is annealed at $100^{\circ} \mathrm{C}$ for $60 \mathrm{~min}$ on a hotplate.

On top of the perovskite, $23 \mathrm{~nm}$ of $\mathrm{C} 60$ and $8 \mathrm{~nm}$ of BCP were deposited by thermal evaporation (Mbraun ProVap 3G) with evaporation rates of ca. 0.1-0.3 $\mathrm{A} / \mathrm{s}$ at a base presurre of under 1E-6 mbar. Finally, $80-100 \mathrm{~nm}$ of $\mathrm{Cu}$ was evaporated at a rate of $0.3-1 \AA$ A $/ \mathrm{s}$ to complete the device structure. The active area is defined by the overlap of ITO and the metal electrode, which is $0.16 \mathrm{~cm}^{2}$.

\section{Device characterization}

Current-voltage characteristics under 1 sun equivalent illumination were recorded using an Oriel LCS-100 class ABB solar simulator in a $\mathrm{N}_{2}$-filled glovebox, calibrated with a Silicon reference cell from Fraunhofer ISE. Cross-checks were performed by measuring some samples in a Wavelabs Sinus-70 LED class AAA solar simulator in air to ensure correct current values. To further reduce possible overestimations, the precise electrode area was determined by microscope imaging using a Nikon Eclipse optical microscope. The average 


\section{WILEY-VCH}

short-circuit mismatch between integrated external quantum efficiency (EQE) values and values from J-V scans is $1-2 \%$. J-V scans were performed with a Keithley 2400 SMU, controlled by a measurement control program written in LabView. The voltage values are swept in $20 \mathrm{mV}$ steps with a integration time of $40 \mathrm{~ms}$ per point and settling time of $40 \mathrm{mV}$ after voltage application, corresponding to a scan speed of $250 \mathrm{mV} / \mathrm{s}$. This fast scan speed is chosen to emphasize possible current-voltage hysteresis. Forward and reverse scan are swept subsequently without interruption.

EQE spectra were recorded with an Oriel Instruments QEPVSI-b system with a Newport 300 W xenon arc lamp, controlled by TracQ-Basic software. The white light is split into monochromatic light by a Newport Cornerstone 260 monochromator and chopped at a frequency of $78 \mathrm{~Hz}$ before being conducted to the PSC surface via optical fibers. The system is calibrated using a Si reference cell with known spectral response before every measurement and cross-checked with an EQE system at the facilities of the Competence Centre Thin-Filmand Nanotechnology for Photo- voltaics Berlin (PVcomB). The electical response of the device under test is measured with a Stanford Research SR830 Lock-In amplifier and evaluated in TracQ. 


\section{WILEY-VCH}

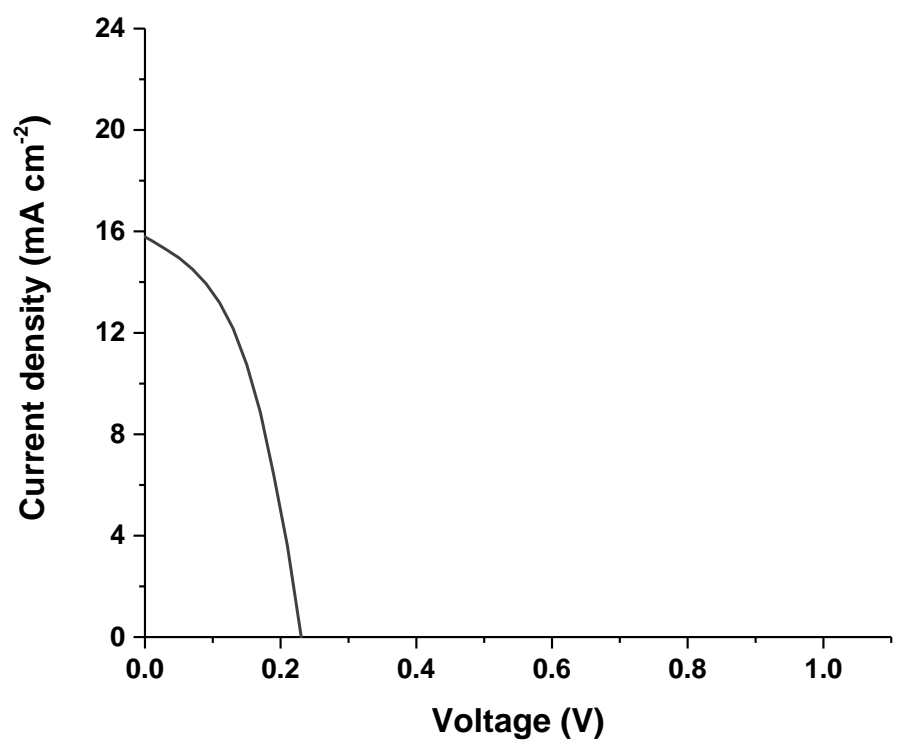

Figure S9. Representative J-V characteristics of HTM-free PSCs (Perovskite directly on ITO). $J_{s c}=16.45 \mathrm{~mA} \cdot \mathrm{cm}^{-2} ; V_{o c}=0.25 \mathrm{~V} ; F F=50.15 \% ; \mathrm{PCE}=2.1 \%$.

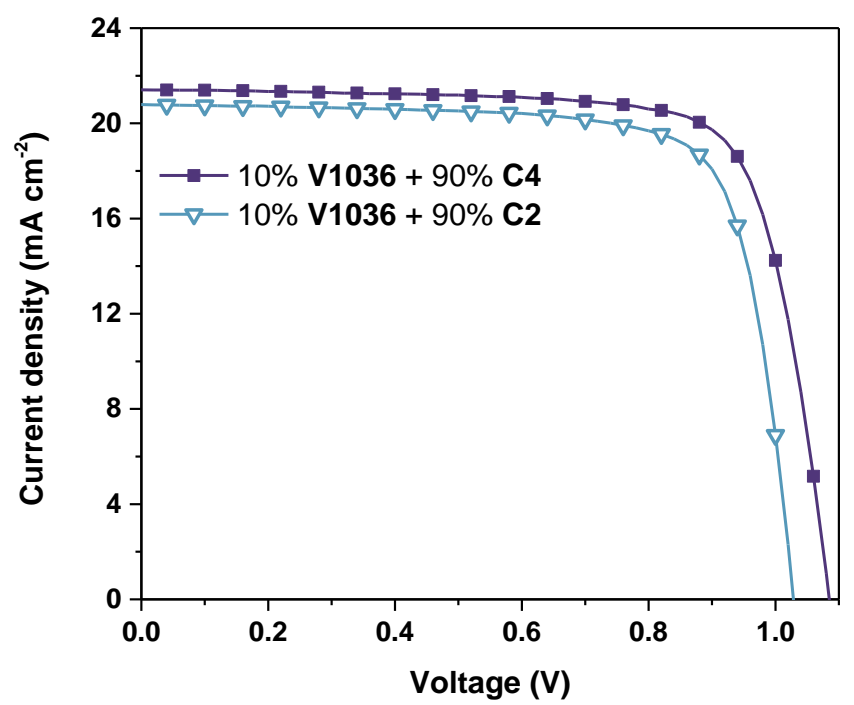

Figure S10. J-V characteristics of the PSCs with $\mathbf{C 4}$ and $\mathbf{C 2}$ aliphatic phosphonic acids. 


\section{WILEY-VCH}

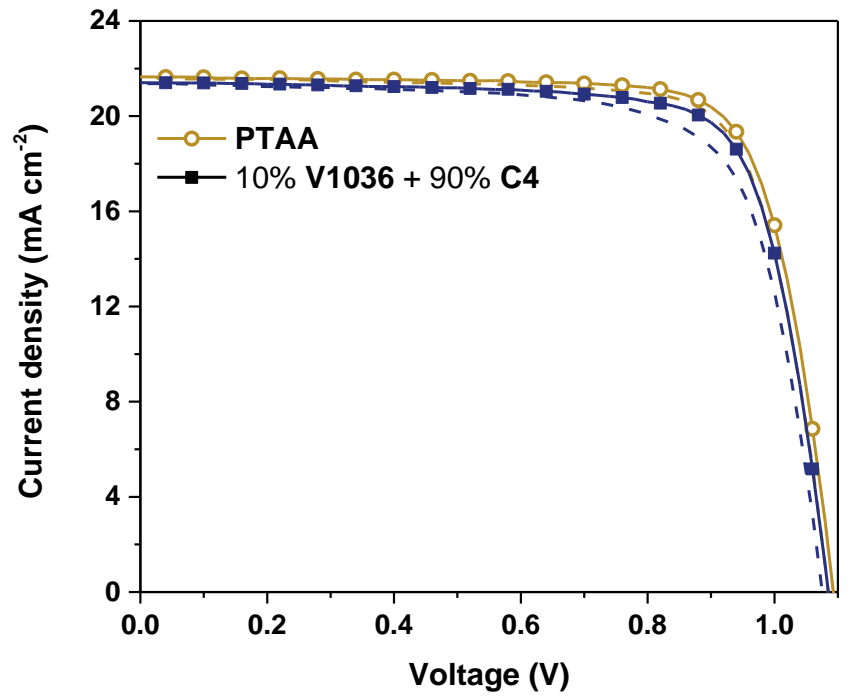

Figure S11. J-V characteristics from forward scan and reverse scan of the best performing PSCs with PTAA and 10\% V1036 90\% C4 SAM HTMs.

\section{Statistical distribution}

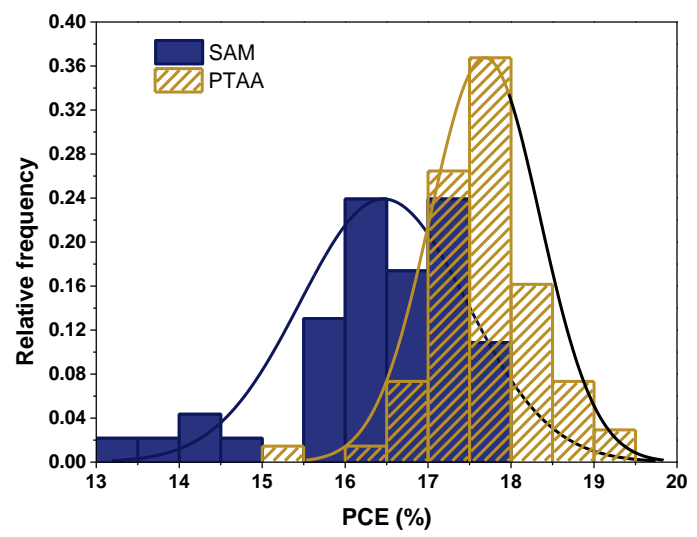

Figure S12. Histogram of PCEs of 41 and 68 cells from several batches for $10 \%$ V1036 $90 \%$ C4 and PTAA respectively. 


\section{WILEY-VCH}

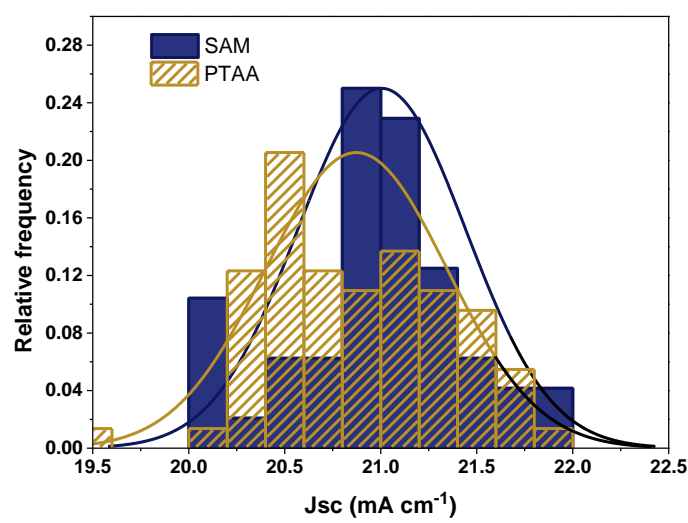

Figure S13. Histogram of $J_{s c}$ of 41 and 68 cells from several batches for $10 \%$ V1036 $90 \% \mathbf{C 4}$ and PTAA respectively.

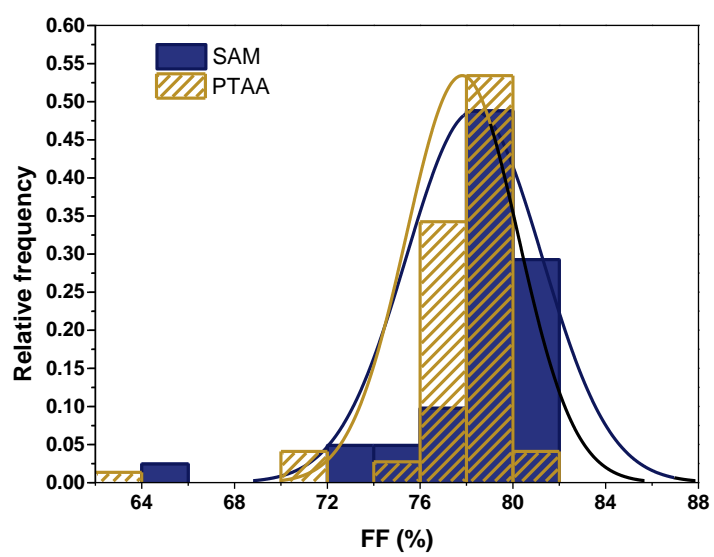

Figure S14. Histogram of $F F$ of 41 and 68 cells from several batches for $10 \%$ V1036 $90 \%$ C4 and PTAA respectively.

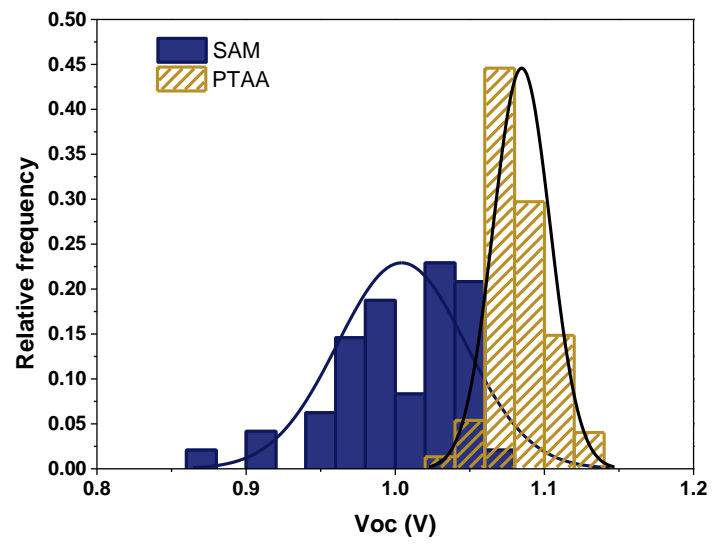

Figure S15. Histogram of $V_{o c}$ of 41 and 68 cells from several batches for $10 \%$ V1036 $90 \%$ C4 and PTAA respectively. 


\section{WILEY-VCH}

\section{Stability measurement}

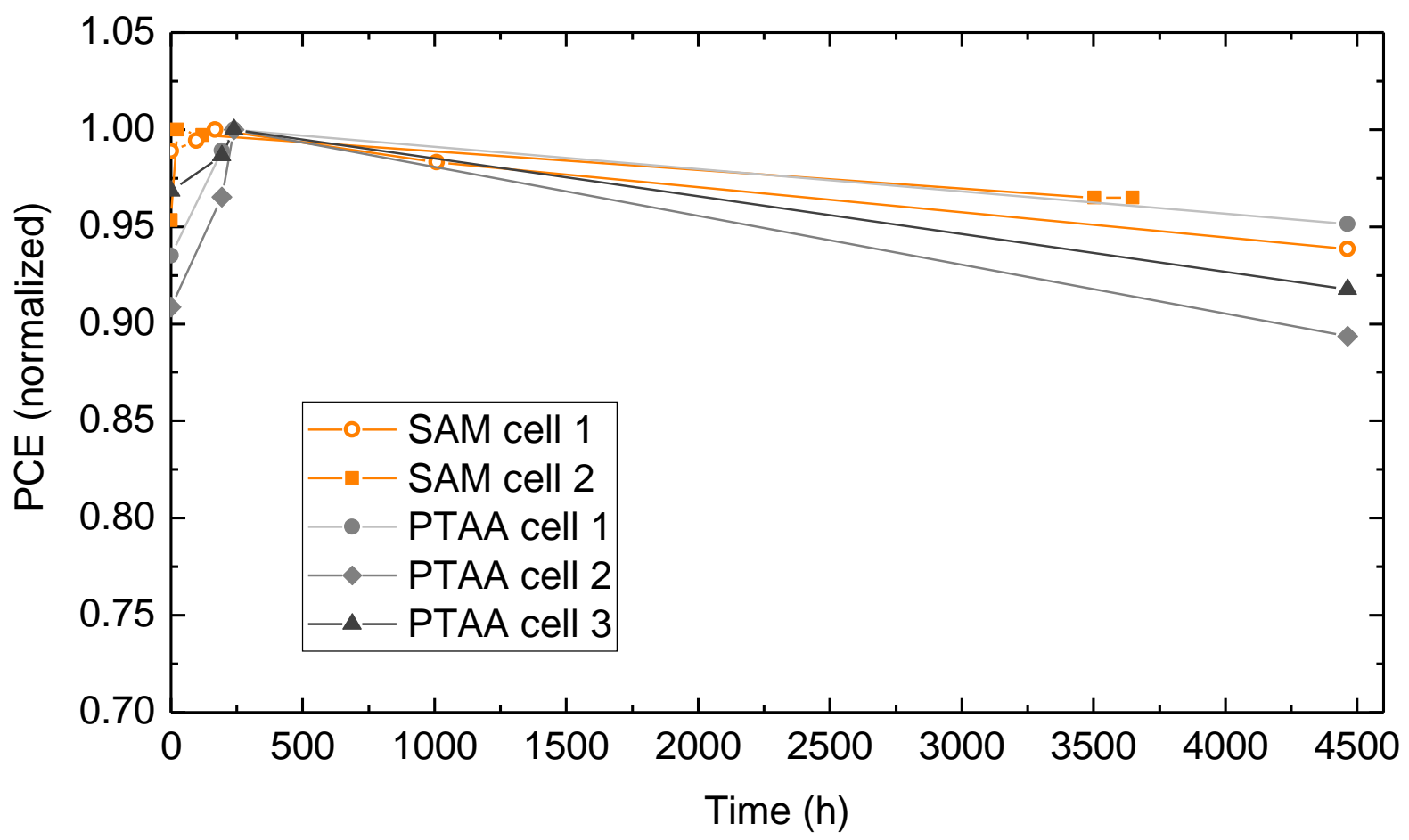

Figure S16. Shelf lifetime of representative PTAA (max. PCE=18.5\%) and SAM cells (max. $\mathrm{PCE}=17.8 \%$ ). The devices were kept in a nitrogen-filled glovebox, dark, 20-26 ${ }^{\circ} \mathrm{C}$. Within the measurement uncertainty and cell-to-cell spread, the stability of cells with either PTAA or SAM HTM is very similar.

\section{Optical simulation of V1036 absorption}
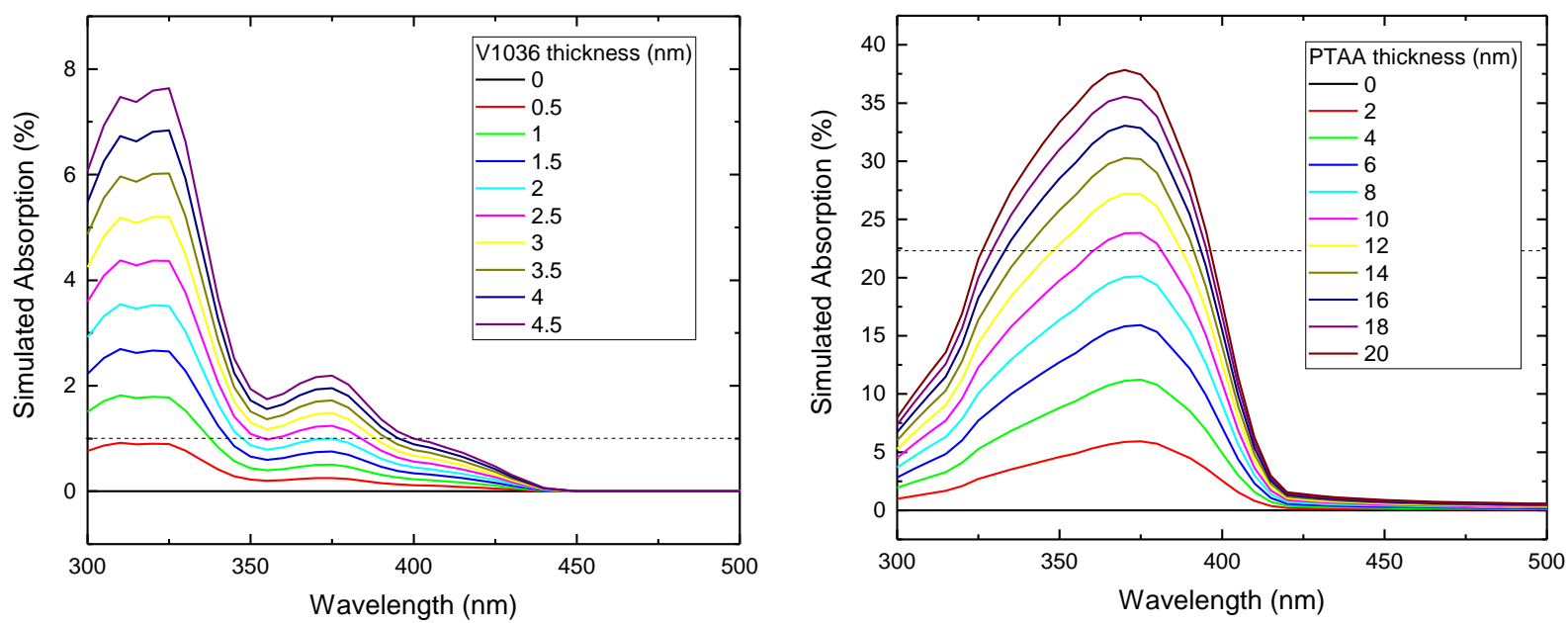

Figure S17. Coherent simulation of the absorption for the monolayer material and for PTAA in a stack of Air/Glass $(1 \mathrm{~mm}) / \mathrm{ITO}(12 \mathrm{~nm}) / \mathrm{HTM} /$ Air with light entering from the glass side. The dashed line in the left plot shows the highest estimated absorption value that could be extracted from the UV/vis measurement shown in the main text. A layer thickness of $2 \mathrm{~nm}$ would be needed to detect $1 \%$ absorption. The dashed line in the right plot shows the 


\section{WILEY-VCH}

measured absorption by the PTAA film. The concluded 8-10 nm PTAA thickness is in close agreement with other reported values for the used PTAA spin-coating procedure. ${ }^{[6]}$

The optical simulation was performed with GenPro $4^{[7]}$ developed at Delft University of

Technology. k data for $\mathbf{V 1 0 3 6}$ was calculated from the molar extinction coefficient $(\varepsilon)$

measurement shown in Figure S17, using a surface packing density of $0.7 \mathrm{~nm}^{2}$ per molecule

and $k=\frac{\alpha \cdot \lambda}{4 \pi}$, where lambda is the wavelength and alpha the absorption coefficient (molar

extinction coefficient multiplied with the molar SAM concentration on the surface). Since the measured absorption in Figure 1B is zero within the measurement uncertainty of 1\%, we can conclude that if there is any absorption by the V1036 layer, the layer thickness must be between 0 and $2 \mathrm{~nm}$ thick. Next to the previous knowledge in literature that such molecules as used here form monolayers on oxides, and with the aspects that we wash the SAM substrates with solvents after annealing, observe a controllable change in contact angle and measure a control of ionization potential, this simulation result together with the absorption measurement further confirms the presence of a single monolayer.
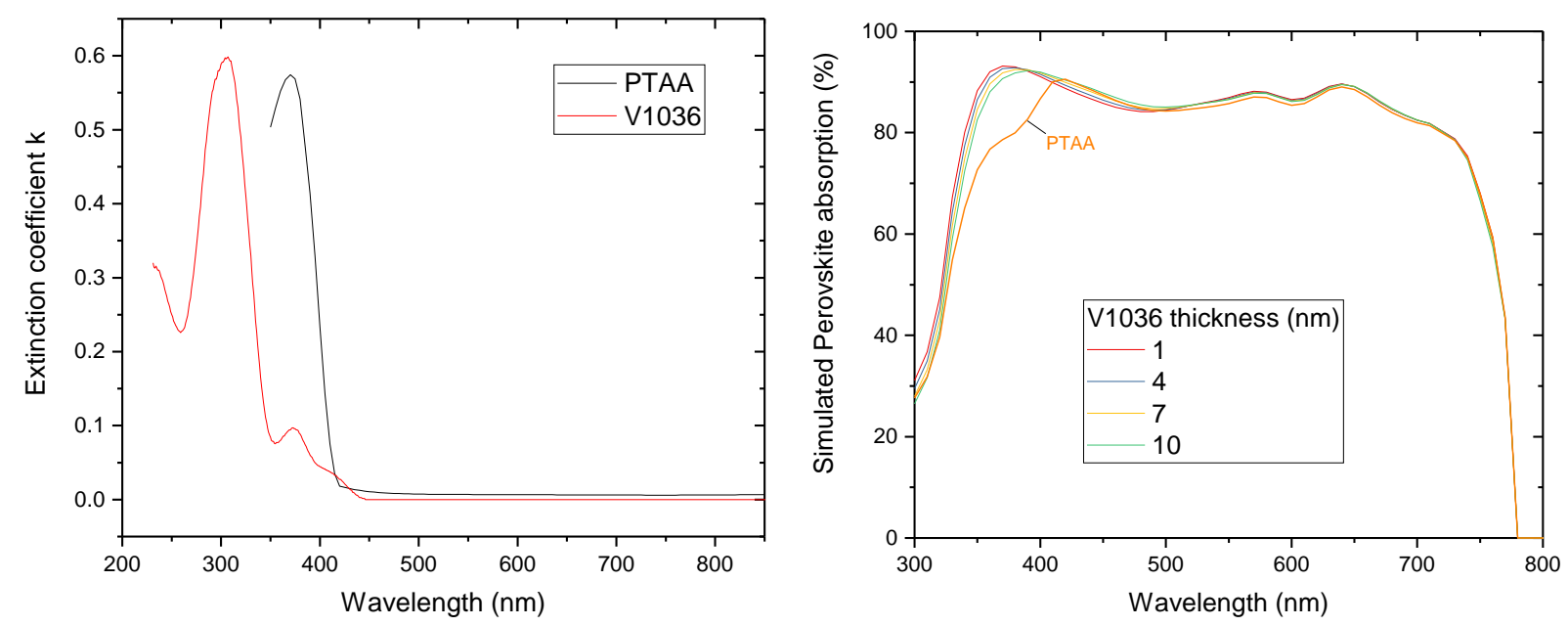

Figure S18. Left: Used extinction coefficients for the simulation. Right: Simulated absorption of the Perovskite layer in the stack Air/Glass $(1 \mathrm{~mm}) / \mathrm{ITO}(120 \mathrm{~nm}) / \mathrm{HTM}(10 \mathrm{~nm}$ for PTAA)/Perovskite(650nm)/C60(23nm)/Cu(100nm). This plot shows that in EQE, V1036 would not be detectable.

\section{Scanning electron microscopy}




\section{WILEY-VCH}

Scanning electron microscope pictures were recorded with a Hitachi S-4100 at an acceleration voltage of $5 \mathrm{kV}$.

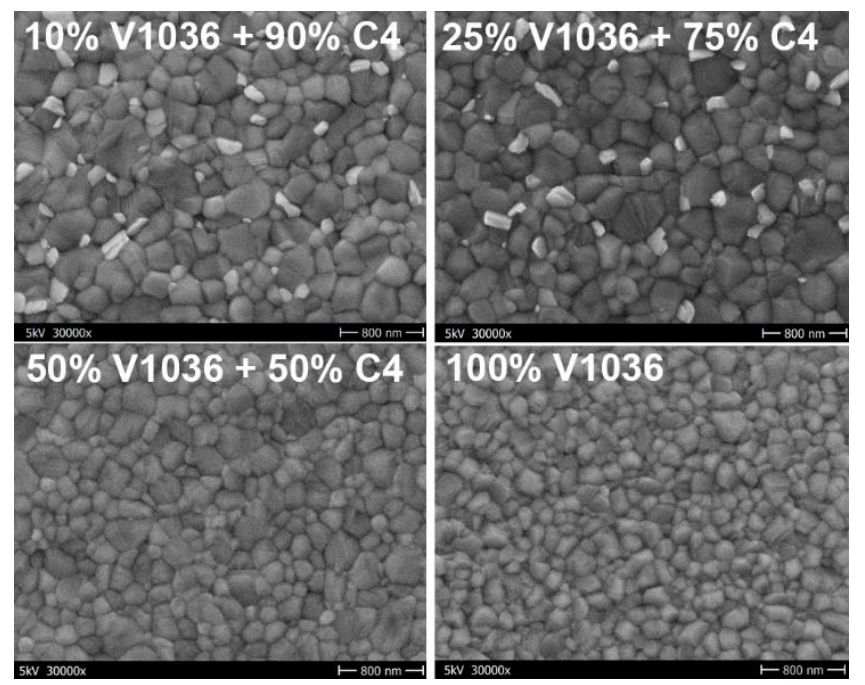

Figure S19. Top-view SEM micrographs of perovskite film, deposited on different SAMcoated substrates.

\section{Computational details}

Geometry optimization was performed using TURBOMOLE version 7.0 software, ${ }^{[8]}$ with Becke's three parameter functional, B3LYP, ${ }^{[9,10]}$ and def2-SVP ${ }^{[11,12]}$ basis set in vacuum. Optimized structures and molecular orbitals were visualized with Avogadro: an open-source molecular builder and visualization tool. Version 1.1.1. ${ }^{[13]}$

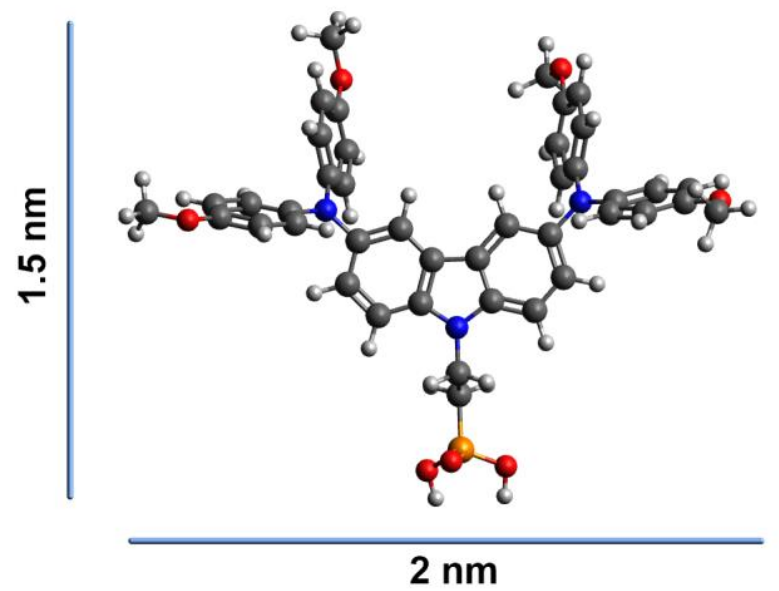

Figure S20. Side-view of the V1036 optimized geometry. 


\section{WILEY-VCH}

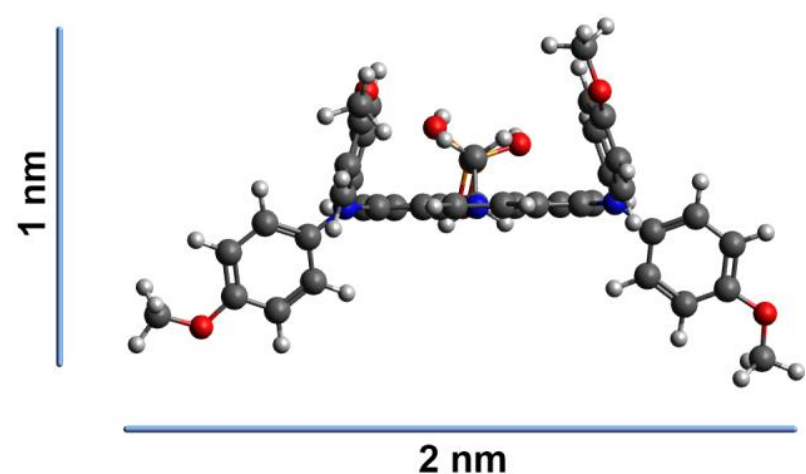

Figure S21. Top-view of the V1036 optimized geometry.

\section{Further electrical characterization}

Figure S22 shows electrochemical impedance (EIS) measurements on two devices comprising a V1036 SAM or PTAA layer respectively, with the rest of the device being equal. For the measurements a FRA-equipped Solarlab XM Potentiostat was used, with a Thorlabs DC2200 LED driver for controlling the LED intensity. These measurements can be used to e.g. characterize interface charge accumulation via fitting with an equivalent circuit model to extract device capacitances and resistances.
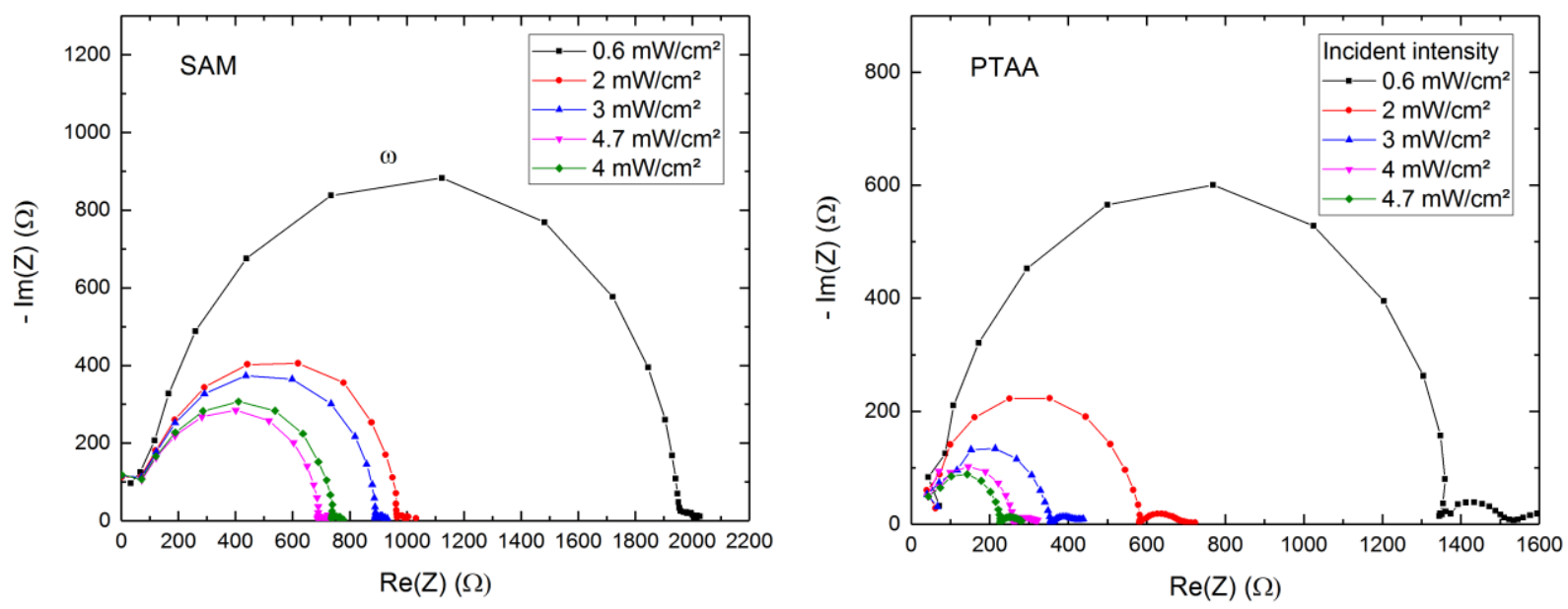

Figure S22. Nyquist plots of electrochemical impedance measurements on a device with a V1036 SAM as the p-layer (left) and PTAA as a p-layer (right). The impedance was measured at open circuit condition for different illumination intensities (orange LED light) with a $10 \mathrm{mV}$ voltage modulation in a frequency range of $0.1 \mathrm{~Hz}$ to $0.5 \mathrm{MHz}$. 


\section{WILEY-VCH}

The equivalent circuit used as a model is shown in Figure $\mathbf{S 2 3}$ and consists of a series resistance $R_{S}$ accounting for cable and contact resistances, a Voigt element $C_{g}-R_{\text {rec }}$ describing the high frequency device response and another capacitance $\mathrm{C}_{1}$ for the slower relaxation processes in the device. ${ }^{[14-16]} \mathrm{C}_{\mathrm{g}}$ is being treated as a constant phase element (CPE) with impedance $\mathrm{Q}^{-1}(\mathrm{Iw})^{-\mathrm{n}}$, where $\mathrm{n}$ is the CPE index describing the ideality of the capacitor and $\mathrm{Q}$ the CPE prefactor, in order to account for the slight depression of the semicircles. ${ }^{[17]}$ Figure S23 shows an exemplary fit to the data displayed as a Bode plot. Special attention has been paid to the high frequency part of the measurements since this is typically connected to interface charge transfer. For every intensity, $\mathrm{R}_{\mathrm{S}}$ was held constant at $65 \mathrm{~W}, \mathrm{R}_{\mathrm{C}}$ at $11 \mathrm{~W}$, and $\mathrm{n}$ was fixed to 0.9. The extracted parameters are plotted in Figure S24. The CPE capacitance is calculated from $R_{\text {rec }}$ and $Q$ and $n$ via $\left(R_{\text {rec }} Q\right)^{1 / n} / R_{\text {rec. }}$.

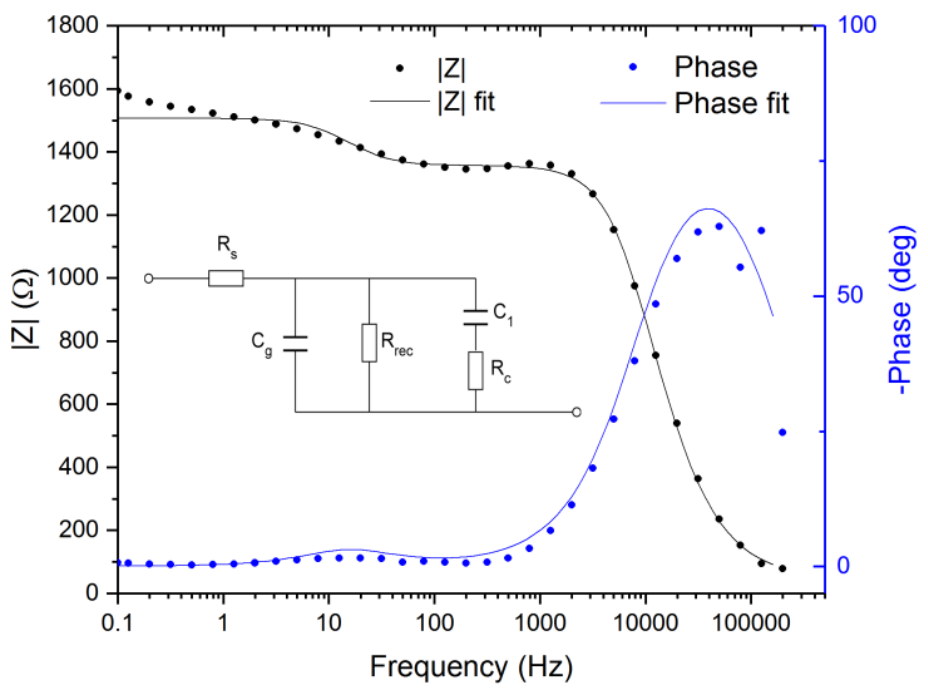

Figure S23. Exemplary fitting result of one EIS curve (PTAA device, $0.6 \mathrm{~mW} / \mathrm{cm}^{2}$ illumination) with using the equivalent circuit shown as an inset. 


\section{WILEY-VCH}
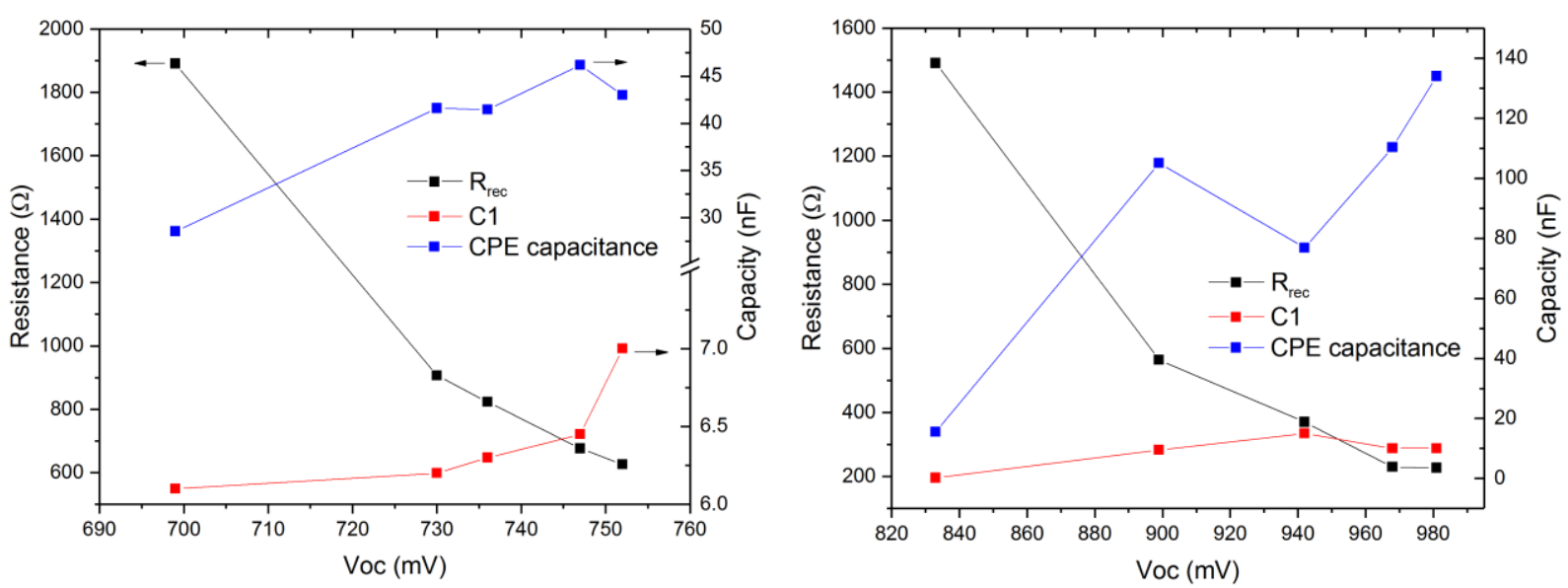

Figure S24. Parameters extracted from fitting the EIS curves with the equivalent circuit shown in Figure S23. Note that the low $V_{O C}$ values stem from low illumination intensities (0.01-0.05 suns). Left: 100\% V1036 SAM, right: PTAA.

It is evident from Figure $\mathbf{S 2 4}$ that both solar cell types show the expected behavior of a rising capacitance and falling recombination resistance with illumination intensity. It can be concluded from the similar (and even lower) CPE capacitance that no charge extraction limitation by charge accumulation is promoted by the SAM. This argument is underlined by the comparison of dark currents shown in Figure S25. SAM-based cells show a significantly lower dark current around short-circuit condition and similarly high injection as PTAA-based devices for applied voltages higher than $V_{O C}$. Note that the lower currents make the SAMbased devices more sensitive to hysteretic phenomena in the dark, which explains the shown slight hysteresis for some of the SAM devices. 


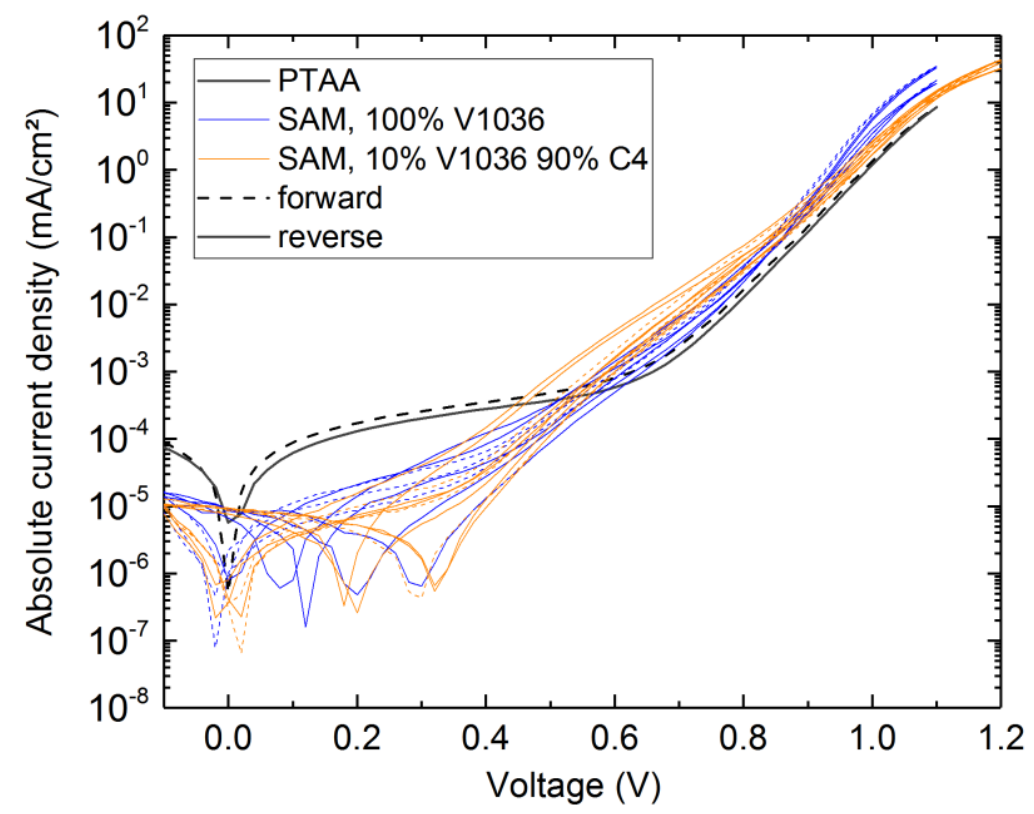

Figure S25. Dark JV measurements comparing a typical curve of a PTAA-based device with several SAM-based cells. Notably, the shunt resistance of the SAM-based devices is higher while showing a similarly high injection efficiency at high forward bias.

\section{Synthesis}<smiles>BrCCn1c2ccc(Br)cc2c2cc(Br)ccc21</smiles>

\section{3,6-dibromo-9-(2-bromoethyl)-9H-carbazole (1)}

3,6-dibromocarbazole (2 g, $6.15 \mathrm{mmol})$ was dissolved in 1,2-dibromoethane (40 $\mathrm{ml})$, and tetrabuthylammonium bromide $(0.198 \mathrm{~g}, 0.62 \mathrm{mmol})$ with $50 \% \mathrm{KOH}$ aqueous solution $(1.72 \mathrm{ml}, 30.77 \mathrm{mmol})$ were added subsequently. Reaction was stirred at $60^{\circ} \mathrm{C}$ for three days (TLC, acetone: $n$-hexane, 1:24, v:v) after each $24 \mathrm{~h}$ adding $0.198 \mathrm{~g}$ of tetrabuthylammonium bromide and $1.72 \mathrm{ml}$ of $50 \%$ aqueous $\mathrm{KOH}$ solution. After completion of the reaction, extraction was done with dichloromethane. The organic layer was dried over anhydrous $\mathrm{Na}_{2} \mathrm{SO}_{4}$ and the solvent was distilled off under reduced pressure. The crude product was 


\section{WILEY-VCH}

purified by column chromatography using acetone: $n$-hexane, $3: 22$, v:v as eluent to give $2.4 \mathrm{~g}$ $(90 \%)$ of white crystalline material $\left(\mathrm{T}_{\mathrm{m}}=153-155^{\circ} \mathrm{C}\right)$.

Anal. calcd for $\mathrm{C}_{14} \mathrm{H}_{10} \mathrm{NBr}_{3}, \%$ : C 38.93; H 2.33; N 3.24; found, \%: C 38.78; H 2.42; N 3.11.

${ }^{1} \mathrm{H}$ NMR $\left(400 \mathrm{MHz}, \mathrm{CDCl}_{3}\right) \delta 8.07(\mathrm{~d}, \mathrm{~J}=1.8 \mathrm{~Hz}, 2 \mathrm{H}) ; 7.54(\mathrm{dd}, \mathrm{J}=8.7,1.9 \mathrm{~Hz}, 2 \mathrm{H}), 7.25(\mathrm{~d}$, $\mathrm{J}=8.7 \mathrm{~Hz}, 2 \mathrm{H}) ; 4.59(\mathrm{t}, \mathrm{J}=7.2 \mathrm{~Hz}, 2 \mathrm{H}) ; 3.62(\mathrm{t}, \mathrm{J}=7.2 \mathrm{~Hz}, 2 \mathrm{H})$.

${ }^{13} \mathrm{C}$ NMR $\left(100 \mathrm{MHz}, \mathrm{CDCl}_{3}\right) \delta 138.83 ; 129.28 ; 123.65 ; 123.38 ; 112.71 ; 110.16 ; 44.75 ; 27.94$.

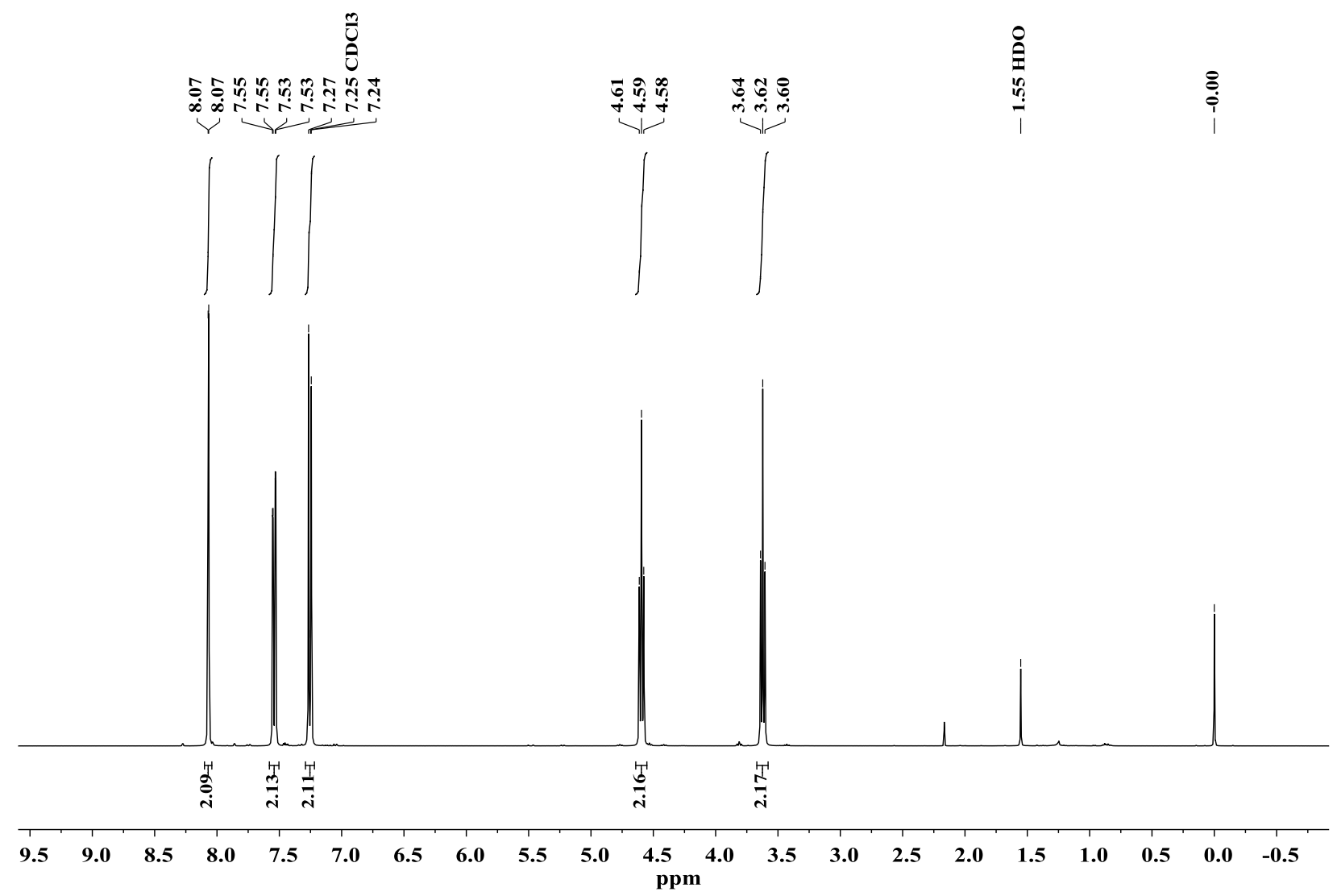




\section{WILEY-VCH}
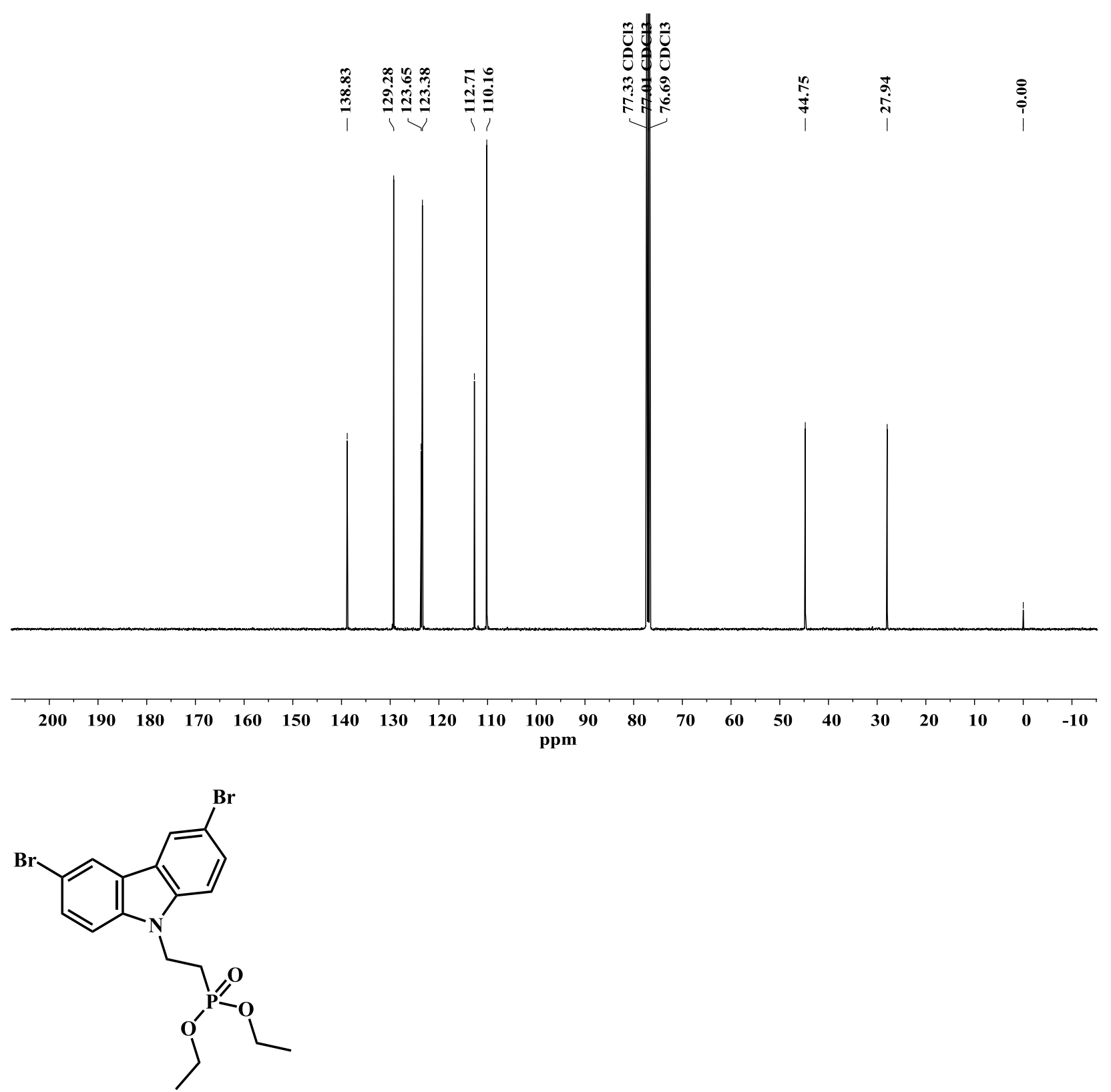

diethyl [2-(3,6-dibromo-9H-carbazol-9-yl)ethyl]phosphonate (2)

Compound 1 (2.4 g, $5.55 \mathrm{mmol})$ was dissolved in triethylphosphite $(20 \mathrm{ml})$ and the reaction mixture was heated at reflux for $18 \mathrm{~h}$. After reaction completion (TLC, acetone: $n$-hexane, 2:3, $\mathrm{v}: \mathrm{v})$ the solvent was distilled off under reduced pressure. The crude product was purified by column chromatography using acetone: $n$-hexane, $7: 18$, v:v as eluent to give $2.56 \mathrm{~g}(95 \%)$ of white crystalline material $\left(\mathrm{T}_{\mathrm{m}}=118-119^{\circ} \mathrm{C}\right)$

Anal. calcd for $\mathrm{C}_{18} \mathrm{H}_{20} \mathrm{NBr}_{2} \mathrm{O}_{3} \mathrm{P}, \%$ : C 44.20; $\mathrm{H} 4.12 ; \mathrm{N} 2.86$; found, \%: $\mathrm{C} 44.09 ; \mathrm{H} 4.26 ; \mathrm{N}$ 3.02 . 


\section{WILEY-VCH}

${ }^{1} \mathrm{H} \mathrm{NMR}\left(400 \mathrm{MHz}, \mathrm{CDCl}_{3}\right) \delta 8.11(\mathrm{~d}, \mathrm{~J}=1.8 \mathrm{~Hz}, 2 \mathrm{H}) ; 7.56(\mathrm{dd}, \mathrm{J}=8.7,1.9 \mathrm{~Hz}, 2 \mathrm{H}) ; 7.30(\mathrm{~d}$, $\mathrm{J}=8.7 \mathrm{~Hz}, 2 \mathrm{H}) ; 4.60-4.49(\mathrm{~m}, 2 \mathrm{H}) ; 4.04(\mathrm{dq}, \mathrm{J}=14.2,7.1 \mathrm{~Hz}, 4 \mathrm{H}) ; 2.28-2.16(\mathrm{~m}, 2 \mathrm{H})$;

$1.24(\mathrm{t}, \mathrm{J}=7.1 \mathrm{~Hz}, 6 \mathrm{H})$.

${ }^{13} \mathrm{C}$ NMR $\left(100 \mathrm{MHz}, \mathrm{CDCl}_{3}\right) \delta 138.65 ; 129.25 ; 123.71 ; 123.37 ; 112.50 ; 110.30 ; 62.01 ; 61.94 ;$

$37.26 ; 37.24 ; 25.88 ; 24.50 ; 16.37 ; 16.31$.

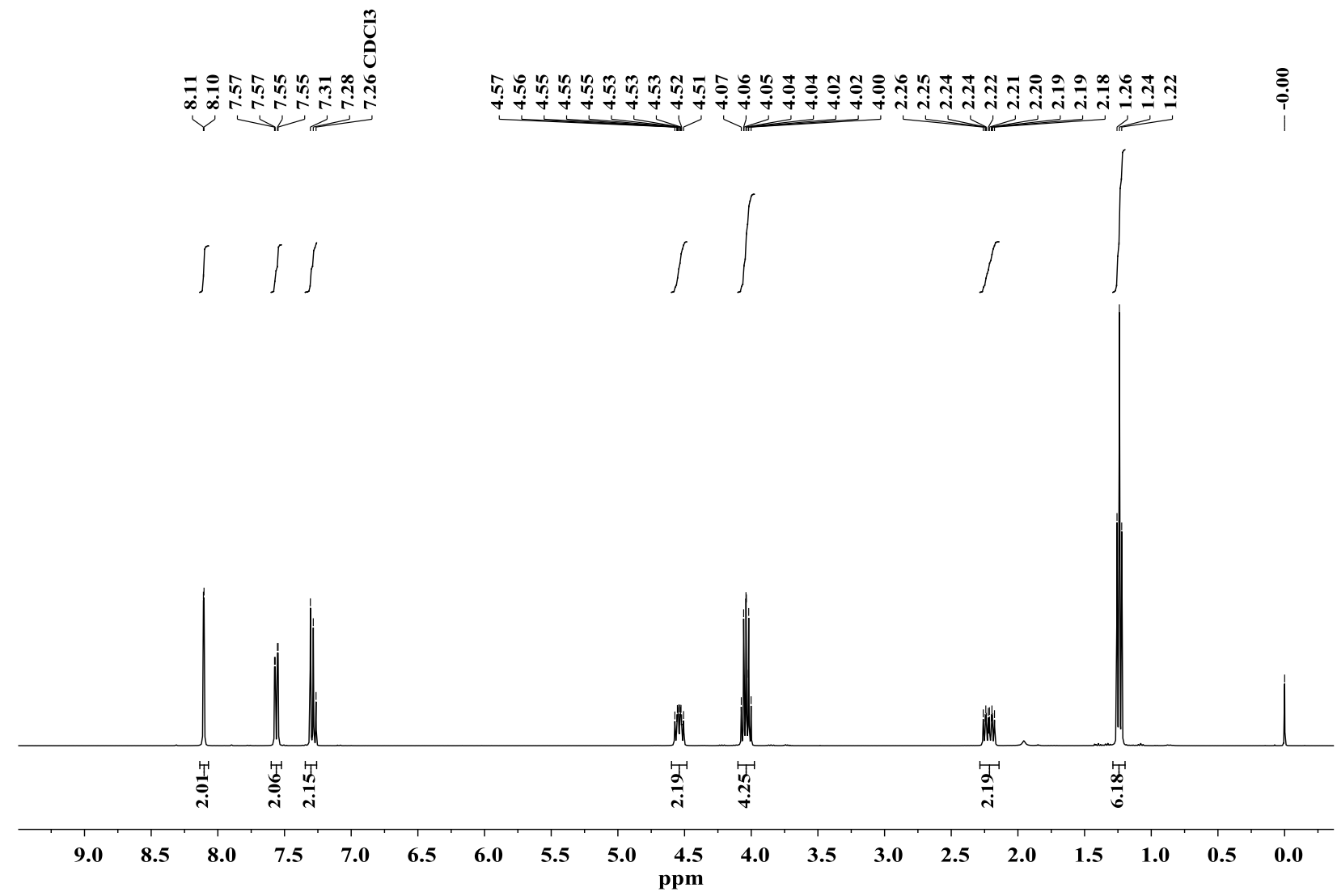




\section{WILEY-VCH}

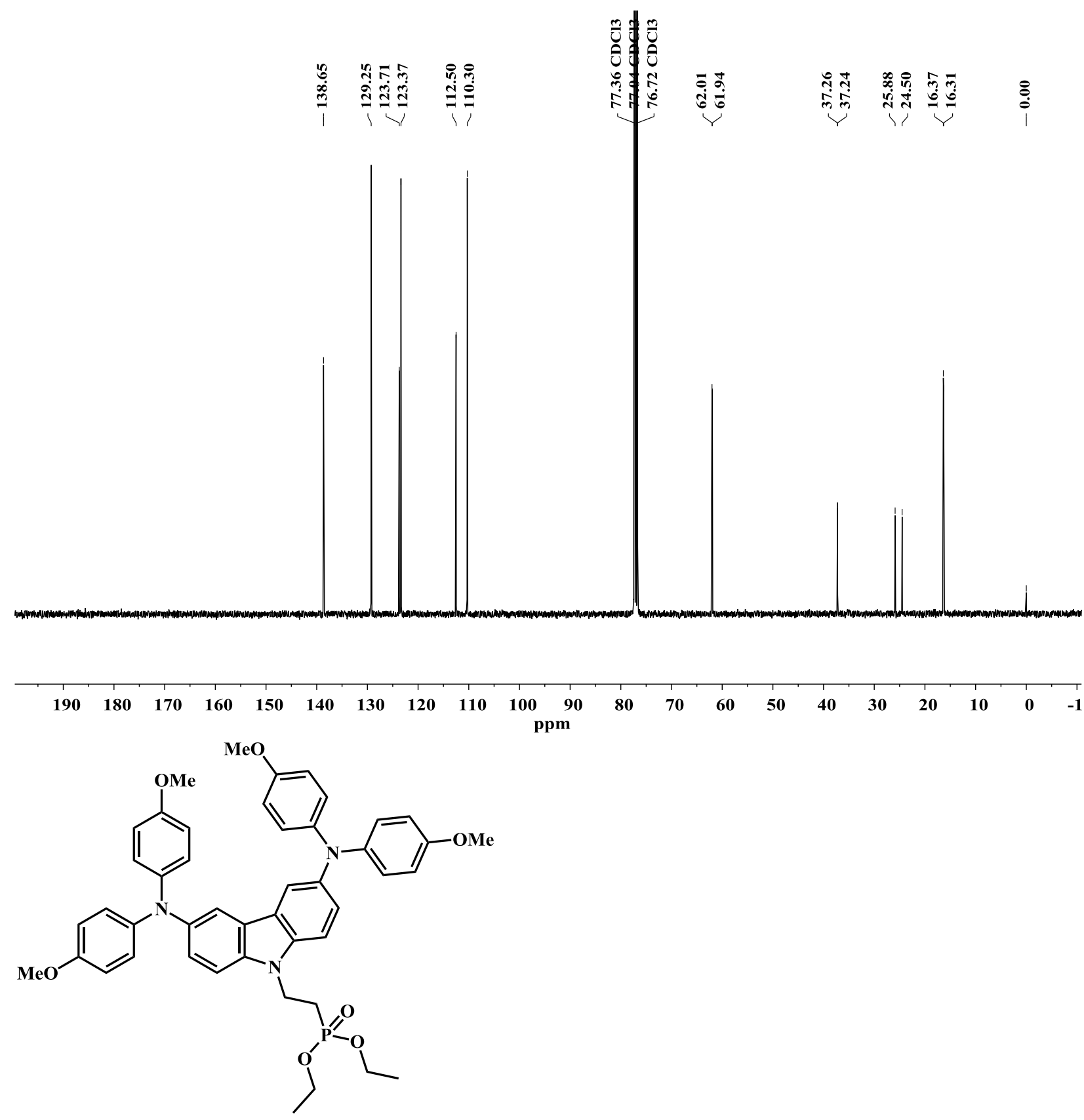

diethyl (2-\{3,6-bis[bis(4-methoxyphenyl)amino]-9H-carbazol-9-yl\}ethyl)phosphonate (3)

A solution of $2(1 \mathrm{~g}, 2.04 \mathrm{mmol})$ and 4,4'-dimethoxydiphenylamine $(1.37 \mathrm{~g}, 6.13 \mathrm{mmol})$ in anhydrous toluene $(50 \mathrm{~mL})$ was purged with argon for $20 \mathrm{~min}$. Afterward, palladium(II) acetate $(0.137 \mathrm{~g}, 0.613 \mathrm{mmol})$, tri-tert-butylphosphonium tetrafluoroborate $(0.35 \mathrm{~g}$, $1.23 \mathrm{mmol})$, and sodium tert-butoxide $(0.59 \mathrm{~g}, 6.13 \mathrm{mmol})$ were added and the solution was refluxed under argon atmosphere for $5 \mathrm{~h}$. After completion (TLC, acetone: $n$-hexane, 2:3, v:v) reaction mixture was filtered through Celite. The solvent was removed under reduced pressure 


\section{WILEY-VCH}

and the crude product was purified by column chromatography using acetone: $n$-hexane, $7: 18$, $\mathrm{v}: \mathrm{v}$ as eluent to give $1 \mathrm{~g}(62.5 \%)$ of greenish powder.

Anal. calcd for $\mathrm{C}_{46} \mathrm{H}_{48} \mathrm{~N}_{3} \mathrm{O}_{7} \mathrm{P}, \%$ : C 70.30; H 6.16; N 5.35, found, \%: C 70.14; H 6.29; N 5.56. ${ }^{1} \mathrm{H}$ NMR (400 MHz, DMSO-d $) \delta 7.64(\mathrm{~d}, J=2.2 \mathrm{~Hz}, 2 \mathrm{H}), 7.46(\mathrm{~d}, J=8.7 \mathrm{~Hz}, 2 \mathrm{H}), 7.11(\mathrm{dd}$, $J=8.7,2.2 \mathrm{~Hz}, 2 \mathrm{H}), 6.86-6.74(\mathrm{~m}, 16 \mathrm{H}), 4.50(\mathrm{dt}, J=13.8,7.3 \mathrm{~Hz}, 2 \mathrm{H}), 3.92(\mathrm{p}, J=7.2 \mathrm{~Hz}$, 4H), $3.67(\mathrm{~s}, 12 \mathrm{H}), 2.26(\mathrm{dt}, J=18.2,7.3 \mathrm{~Hz}, 2 \mathrm{H}), 1.12(\mathrm{t}, J=7.0 \mathrm{~Hz}, 6 \mathrm{H})$.

${ }^{13} \mathrm{C}$ NMR (101 MHz, DMSO) $\delta 154.16,142.08,140.25,136.67,124.39,123.67,122.90$, $116.94,114.60,110.28,61.20,61.14,55.15,28.62,16.13,16.07$.

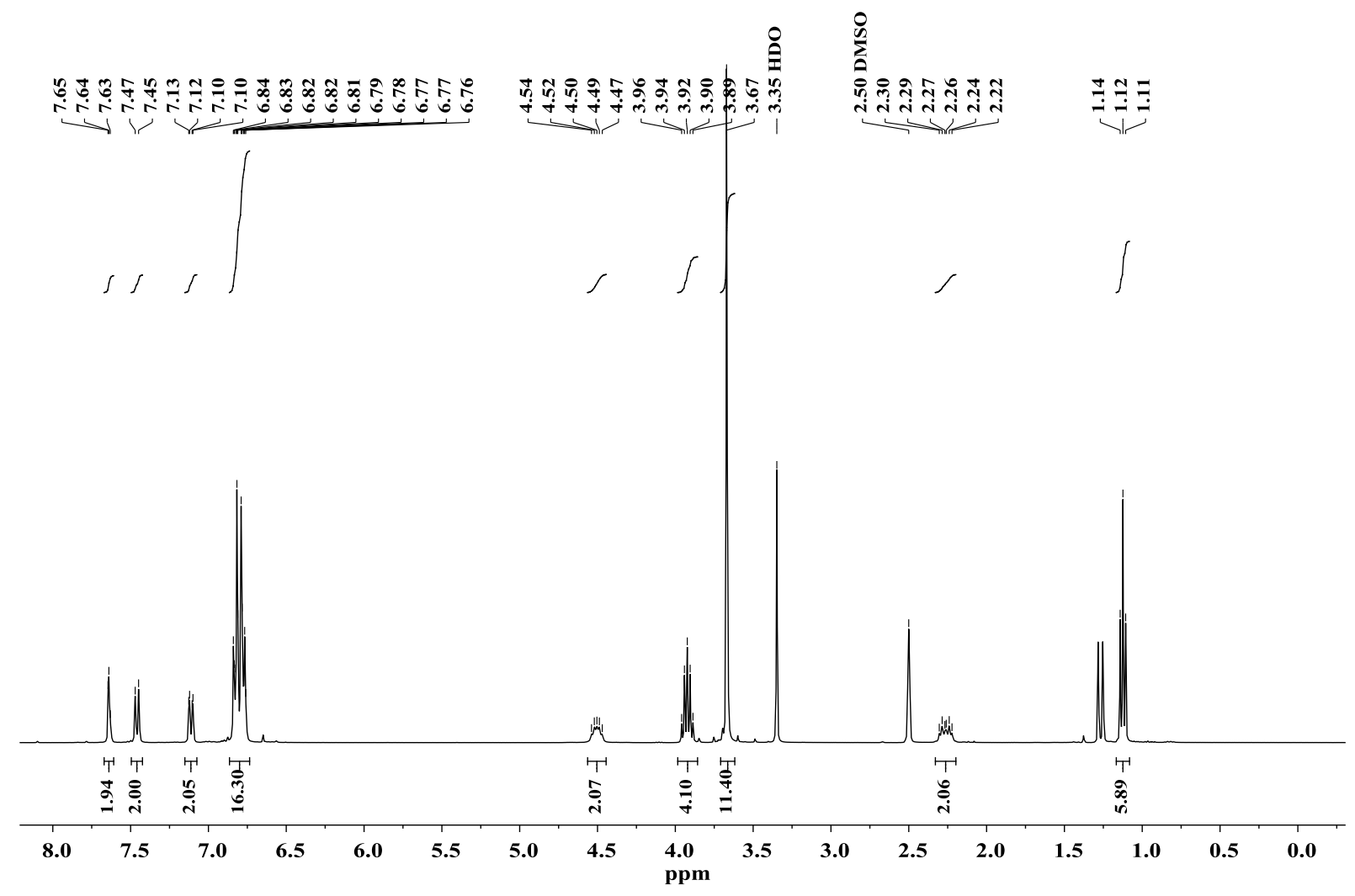




\section{WILEY-VCH}

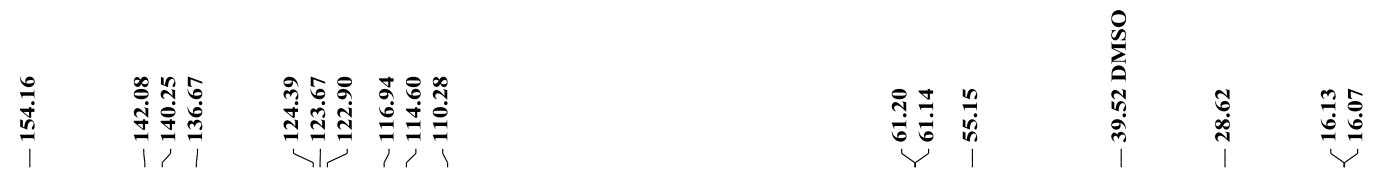

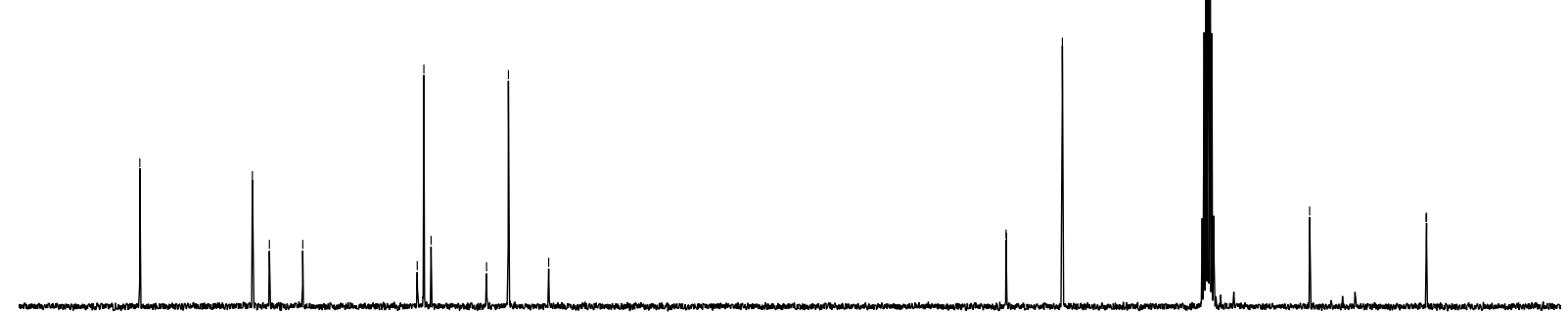

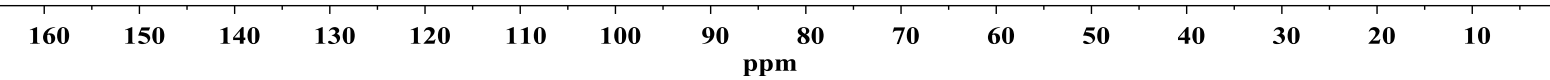<smiles>COc1ccc(N(c2ccc(OC)cc2)c2ccc3c(c2)c2cc(N(c4ccc(OC)cc4)c4ccc(OC)cc4)ccc2n3CCP(=O)(O)O)cc1</smiles>

(2-\{3,6-bis[bis(4-methoxyphenyl)amino]-9H-carbazol-9-yl\}ethyl)phosphonic acid

$3(0.4 \mathrm{~g}, 0.51 \mathrm{mmol})$ was dissolved in dry 1,4-dioxane $(15 \mathrm{ml})$ under argon. Afterwards, bromotrimethylsilane $(0.67 \mathrm{ml}, 5.08 \mathrm{mmol})$ was added dropwise. Reaction was kept for $24 \mathrm{~h}$ at $25^{\circ} \mathrm{C}$ under argon atmosphere. Afterwards solvent was distilled off under reduced pressure, solid residue was dissolved in methanol $(10 \mathrm{ml})$ and distilled water was added dropwise (10 ml), until solution became opaque, and was stirred for $15 \mathrm{~h}$. Product was filtered off and washed with water to give $0.321 \mathrm{~g}(86 \%)$ of greenish powder.

Anal. calcd for $\mathrm{C}_{42} \mathrm{H}_{40} \mathrm{~N}_{3} \mathrm{O}_{7} \mathrm{P}, \%$ : C 69.13; H 5.52; N 5.76, found, \%: C 68.89; H 5.38; N 5.53. 


\section{WILEY-VCH}

${ }^{1} \mathrm{H}$ NMR (400 MHz, DMSO- $\left.d_{6}\right) \delta 7.64$ (s, 2H), 7.42 (d, $\left.J=8.8 \mathrm{~Hz}, 2 \mathrm{H}\right), 7.15-7.07$ (m, 2H), $6.87-6.74(\mathrm{~m}, 16 \mathrm{H}), 4.50-4.44(\mathrm{~m}, 2 \mathrm{H}), 3.67(\mathrm{~s}, 12 \mathrm{H}), 2.02(\mathrm{dt}, J=17.3,8.0 \mathrm{~Hz}, 2 \mathrm{H})$.

${ }^{13} \mathrm{C}$ NMR (100 MHz, DMSO-d6) $\delta$ 154.16; 142.09; 140.22; 1366; 124.60; 123.66; 122.88;

$117.15 ; 114.63 ; 110.01 ; 66.36 ; 55.16$.
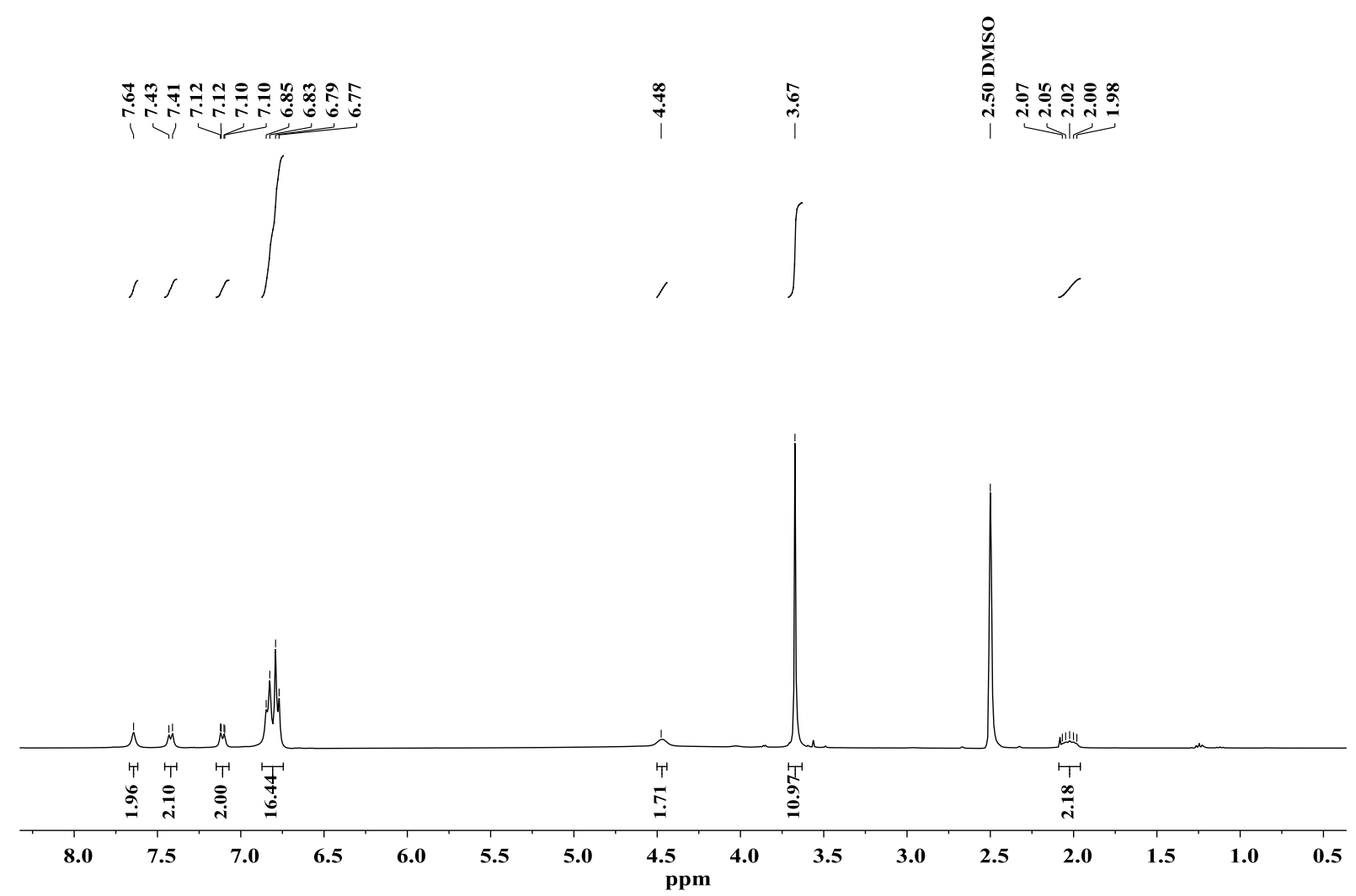


\section{WILEY-VCH}

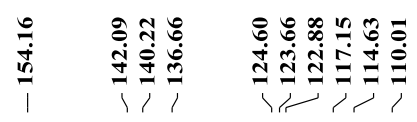

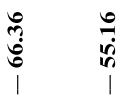

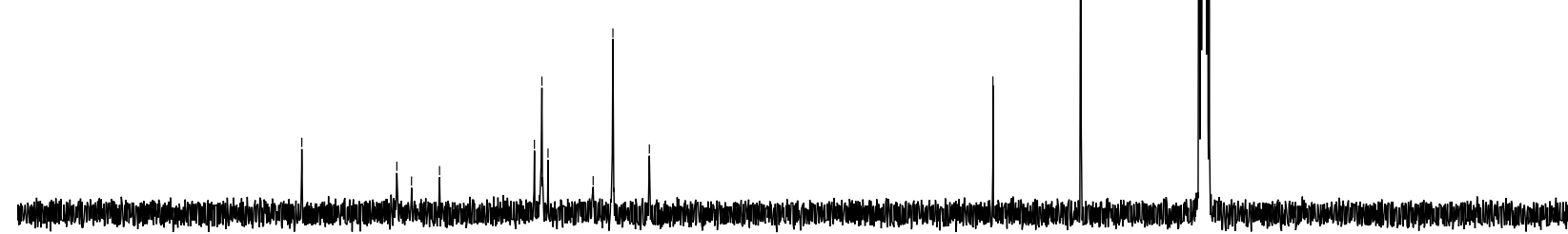

9018

$\begin{array}{lll}70 & 160 & 150\end{array}$

140130

$120 \quad 110 \quad 10$ ppm

$80 \quad 70 \quad 60$

5040

$\begin{array}{llll}10 & 10 & 0\end{array}$ 


\section{WILEY-VCH}

\section{Literature}

[1] G. Niaura, Z. Kuprionis, I. Ignatjev, M. Kažemėkaitè, G. Valincius, Z. Talaikytė, V. Razumas, A. Svendsen, J. Phys. Chem. B 2008, 112, 4094.

[2] M. Cordona, L. Ley, Top. Appl. Phys. 1978, 26, 1.

[3] E. Miyamoto, Y. Yamaguchi, M. Yokoyama, Electrophotography 1989, 28, 364.

[4] M. Kirkus, M.-H. Tsai, J. V. Grazulevicius, C.-C. Wu, L.-C. Chi, K.-T. Wong, Synth. Met. 2009, 159, 729.

[5] M. Saliba, T. Matsui, J.-Y. Seo, K. Domanski, J.-P. Correa-Baena, M. K. Nazeeruddin, S. M. Zakeeruddin, W. Tress, A. Abate, A. Hagfeldt, M. Grätzel, Energy Environ. Sci. 2016, 9, 1989.

[6] M. Stolterfoht, C. M. Wolff, Y. Amir, A. Paulke, L. Perdigón-Toro, P. Caprioglio, D. Neher, Energy Environ. Sci. 2017, 10, 1530-1539.

[7] R. Santbergen, T. Meguro, T. Suezaki, G. Koizumi, K. Yamamoto, M. Zeman, IEEE J. Photovoltaics 2017, 7, 919-926.

[8] R. Ahlrichs, M. Bär, M. Häser, H. Horn, C. Kölmel, Chem. Phys. Lett. 1989, 162, 165169.

[9] C. Lee, W. Yang, R. G. Parr, Phys. Rev. B 1988, 37, 785-789.

[10] A. D. Becke, J. Chem. Phys. 1993, 98, 5648-5652.

[11] A. Schäfer, H. Horn, R. Ahlrichs, J. Chem. Phys. 1992, 97, 2571-2577.

[12] F. Weigend, R. Ahlrichs, K. A. Peterson, T. H. Dunning, R. M. Pitzer, A. Bergner, Phys. Chem. Chem. Phys. 2005, 7, 3297.

[13] M. D. Hanwell, D. E. Curtis, D. C. Lonie, T. Vandermeersch, E. Zurek, G. R. Hutchison, J. Cheminform. 2012, 4, 17.

[14] E. Ghahremanirad, A. Bou, S. Olyaee, J. Bisquert, J. Phys. Chem. Lett. 2017, 8, 14021406.

[15] A. Pockett, G. E. Eperon, T. Peltola, H. J. Snaith, A. Walker, L. M. Peter, P. J. Cameron, J. Phys. Chem. C 2015, 119, 3456-3465.

[16] I. Zarazúa, S. Sidhik, T. Lopéz-Luke, D. Esparza, E. De la Rosa, J. Reyes-Gomez, I. Mora-Seró, G. Garcia-Belmonte, J. Phys. Chem. Lett. 2017, 8, 6073-6079.

[17] J. Bisquert, F. Fabregat-Santiago, in Dye-Sensitized Solar Cells, (Ed: K. Kalyanasundaram), EPFL press, Lausanne, Switzerland 2010, pp. 457-555. 